\title{
Extension of Spencer's Circular Model to Stability Analysis of Landslides with Multicircular Slip Surfaces
}

\author{
Zhiqiang Fan $\mathbb{D}^{1,},{ }^{1,2}$ Huiming Tang $\mathbb{D}^{1,3}$ Yingming Yang, ${ }^{3}$ Yanhao Zheng, ${ }^{2}$ Qinwen Tan, ${ }^{3}$ \\ and Tao Wen ${ }^{4}$ \\ ${ }^{1}$ Faculty of Engineering, China University of Geosciences, No. 388 Lumo Road, Wuhan, Hubei 430074, China \\ ${ }^{2}$ Department of Civil, Environmental and Geomatic Engineering, University College London, Gower St., Bloomsbury, \\ London WC1E 6BT, UK \\ ${ }^{3}$ Three Gorges Research Center for Geohazards of Ministry of Education, China University of Geosciences, No. 388 Lumo Road, \\ Wuhan, Hubei 430074, China \\ ${ }^{4}$ Department of Geology, School of Geosciences, Yangtze University, Wuhan, Hubei 430100, China
}

Correspondence should be addressed to Huiming Tang; tanghm@cug.edu.cn

Received 2 March 2020; Accepted 28 April 2020; Published 28 May 2020

Academic Editor: Enrico Conte

Copyright (C) 2020 Zhiqiang Fan et al. This is an open access article distributed under the Creative Commons Attribution License, which permits unrestricted use, distribution, and reproduction in any medium, provided the original work is properly cited.

This paper presents a new limit equilibrium method based on analysis of landslides with multicircular slip surfaces in the Three Gorges Reservoir area, China. An important innovation of this method is that the rigid sliding mass is divided into numerous interrelated Spencer's circles sharing the same factor of stability, so that each of them possesses a real centre of rotation and an independent inclination of interslice forces. The analysis is accomplished by iterations to satisfy both force and moment equilibrium for each circle. Two real cases were then adopted to verify the effectiveness of the method in the analysis of both slope stability and the design forces on piles. Factors influencing the performance of the method were also investigated, which reveal that the concavity of the local slip surface near the slope toe has a major impact. The importance of the proximity between the actual and the fitted sliding surfaces was highlighted for ensuring accuracy of the method when extended to the real cases.

\section{Introduction}

Limit equilibrium methods of slices (LEMS) to assess slope stability have been prevalent for decades $[1,2]$. The earliest slices model was based on a circular slip-surface because some evidence from slope failures in Sweden suggested that the failure surface is often circular in longitudinal section [3-5]. Perhaps for its concise geometrical morphology and equilibrium conditions (notably the moment equilibrium about a real centre of rotation), the circular model has been adopted widely for both capturing the critical failure surfaces and developing stability charts (e.g., [6-8]). However, the large number of noncircular slip-surfaces being found in practice highlights the limitation of the circular model in the stability analysis of landslides with complicated slip-surfaces. As a result, many general limit equilibrium models have been proposed through better and more realistic assumptions $[9,10]$.
For example, the Morgenstern \& Price (M\&P) method is the most popular, which is noted for its rigorous derivation for both the equilibrium equations of forces and moments (e.g., [11-13]). An innovation of this method is to depict the inclinations of the interslice forces as a function $\lambda f(x)$, where $\lambda$ is a scaling parameter and $f(x)$ reflects its shape characteristic, such that the solution for the factor of stability (FoS) is a statically determinate problem. But it did not specify what kind of functions of inclinations should be selected for a specific slope, and its complexity is also a challenge for some civil engineers [14]. Spencer's method $[8,15]$ is regarded as a special case of the M\&P method for its assumption of a constant inclination of the interslice forces (i.e., $f(x)=1$ ). Although this option greatly simplifies the calculations and makes them convenient for the circular slip-surfaces, it is sometimes approximate for complicated slip-surfaces. Janbu's method [16] considers the local moment equilibrium instead of the total one, 
and the locations where the resultant interslice forces act (the line of thrust) are introduced to render the problem determinate. Meanwhile continuous iterations and nonconvergence involved in this method might be encountered for some more complex slip-surfaces. Although improvements have been made for overcoming the limitation $[17,18]$, the introduction of more complicated assumptions will inhibit its wider use. Fredlund and Krahn [19] incorporate the commonly used methods of slices into a generalised framework, but when extending the equations of FoS of the classical circular model to the cases of composite failure surfaces, a drawback that the selection of a fictitious rotation centre has an effect on the computations appears [20]. By employing the expression of normal stress on the sliding surface, important works have also been done for the global analysis method when considering the stability evolution problems of landslides which are under the combined effect of water level fluctuations and rainfall [2]. Significant progress has been obviously made for LEMS in the past decades, but improvements can still be made if we review and take advantage of the original circular model, which has been unconsciously neglected by many of the more recent innovations.

Recently, landslide investigation in the Three Gorges Reservoir (TGR) area of China reveals that a stepped slipsurface is often generated in colluvial materials, which are widespread in the soft and hard interbedded rocks [21, 22]. Tan et al. [23] highlight that the differential weathering effect on interbedded rocks should be responsible for such phenomena because it helps to create a topographic condition for the formation of a sliding mass, together with its particular sliding surface (see Figure 1). Some researchers have realised the significance of such slip-surfaces in the engineering design of stabilising piles because of some evidence that indicates these stepped surfaces can be fitted by one or more similar circular functions (e.g., [22-24]). For example, Li et al. [22] adopt a bicircular model to fit the sliding surfaces of colluvial landslides, based on which the design driving force (DDF) of piles is determined by selecting the difference in values of residual driving force between the expected safety state and the ultimate state of the slope. Tan et al. [23] prove that several independent arcs can be used to fit the original sliding surface. Moreover, they consider a gently inclined transition between two arcs is a suitable location for installing stabilising piles. However, these researches are limited to studying the function of the multicircular sliding surface on the design of stabilising piles; a simple and practical model that is implied within it for analysing stability has been neglected, which is also useful for determining the DDF of piles.

In this paper, a novel method of stability analysis extended from Spencer's circular model [8] is proposed for accommodating some landslides with multicircular slipsurfaces, which are especially widespread in the TGR area of China. The novelty of this method is accomplished by dividing the rigid sliding mass into numerous interrelated Spencer's circles sharing the same FoS, so that each of them possesses a real centre of rotation and an independent inclination of interslice forces. By this way, the drawback that a fictitious rotation centre and a global inclination of interslice are selected in classical Spencer's [8, 15] or Fredlund's [20]

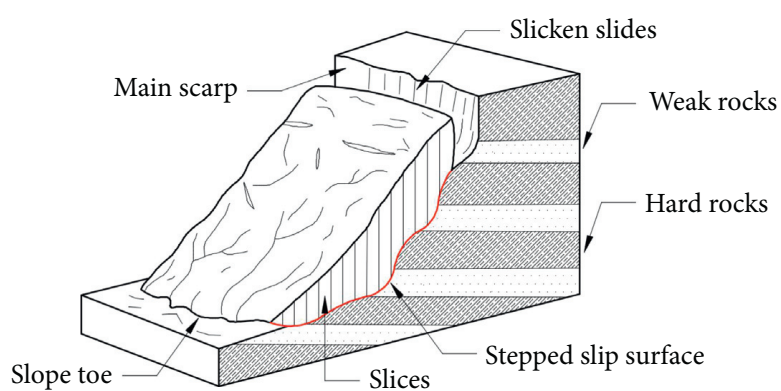

Figure 1: Schematic diagram for a landslide with a stepped slipsurface (modified from [23]).

method for stability analysis can be overcome. Apart from the stability analysis, an expanded procedure of the new method for deriving the DDF of stabilising piles was also demonstrated as a proof of the comprehensiveness that the new method possesses. The validity of the new method for analysing the stability and for deriving the forces of landslides was then verified by two real cases. Additionally, the following four aspects were discussed: (i) the main factors influencing the performance of the new method; (ii) considerations needed in its practical application; (iii) the inclination rule for the interslice forces; and (iv) clarifying two problems regarding the selection of pile's interval and the assessment of stability of landslide reinforced with piles, respectively.

\section{Methodology}

The new method for stability analysis is derived from a novel computational model, where Spencer's circle [8] is employed as the basic element.

2.1. Computational Model. For capturing the characteristics of multicircular sliding surface, an ideal profile is adopted in Figure 2(a), where the entire sliding surface is divided into numerous individual slip-circles. Each slip-circle, together with the vertical sliding mass overlying, is therefore regarded as a particular Spencer's circle and is sliced (Figure 2(b)). "Link-forces" between every two circles are employed to relate the circles to each other, such as $Z_{a}$ and $Z_{b}$ connecting circle.1, circle.2, and circle.3 (Figure 2(b)).

Before analysis, four stipulations are needed:

(a) The forces acting on the slice pass through the middle point of slice base, and each circle has an independent constant of $\theta_{m}$; for example, $\theta_{1}$ is used for circle.1 and $\theta_{2}$ is used for circle.2 (Figure 2(b)).

(b) Following the order of $m$, the "link-force" is treated as an interslice force of the circle in front of it, so its inclination is equal to $\theta_{m}$ of that circle. For example, the inclination of $Z_{a}$ is $\theta_{1}$ (Figure 2(b)).

(c) The entire sliding mass overlying the sliding surface is treated as a rigid body, so the FoS is the same and should satisfy both force and moment equilibrium for each circle. 


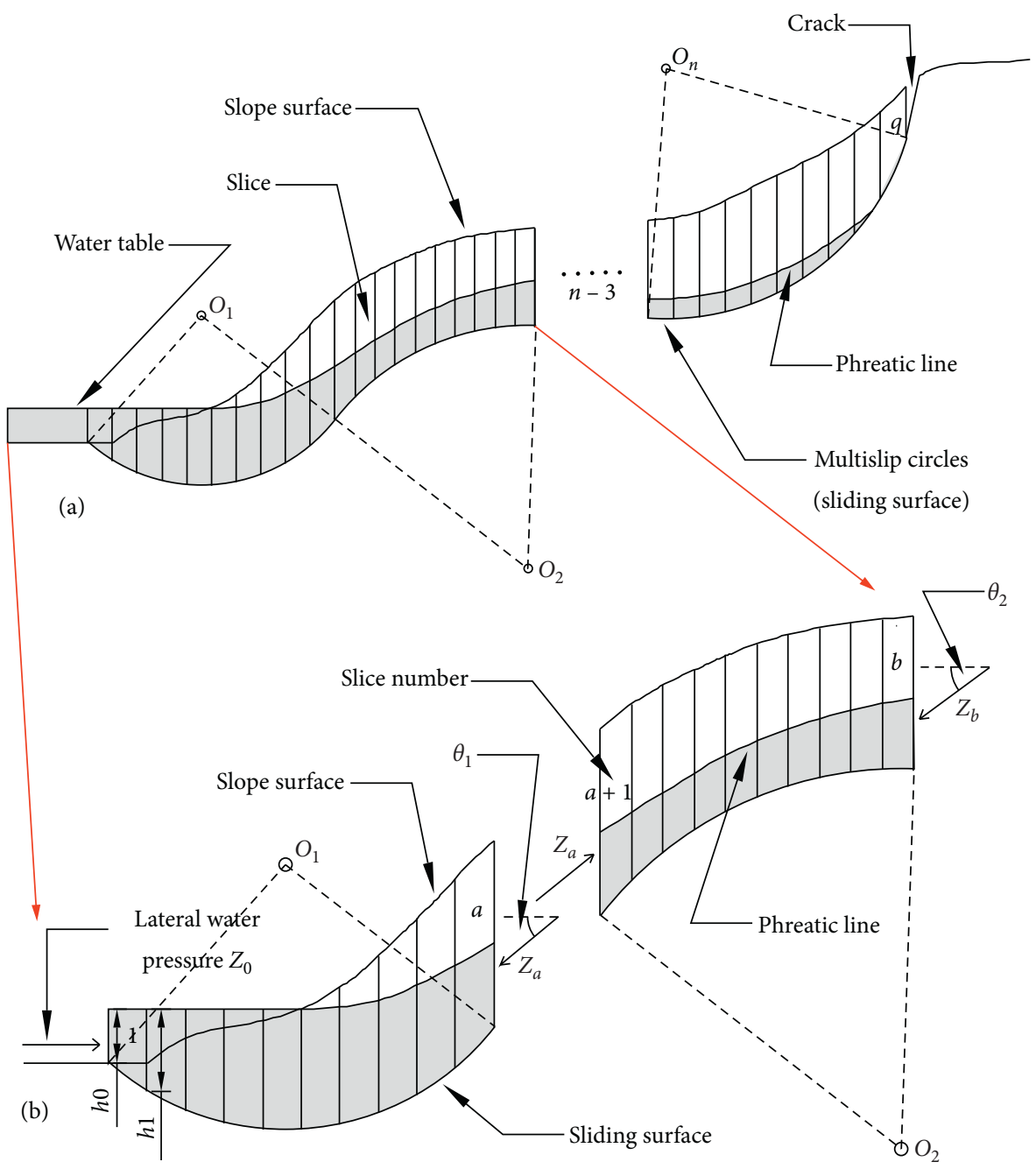

Figure 2: (a) Ideal calculation profile. (b) Force-relationship between the circles.

(d) For slices submerged under water, an overlying vertical water body of the same width is superimposed on it to form a new slice for calculation. The hydraulic height $h$ on both sides of the slice is recorded from the water surface to slice base, such as $h_{0}$ or $h_{1}$ for slice.1 (Figure 2(b)).

A universal analysis diagram for slice. $i$ is given in Figure 3(a), where the forces illustrated are the weight $W_{i}$, the total reaction $P_{i}$ normal to the slice base (composed of the buoyant force $U_{i}$ and the effective force $P_{i}^{\prime}$ ), the mobilized shear force $S_{i} / F$, and the forces on both sides of the slice $\left(Z_{i-1}\right.$ and $\left.Z_{i}\right)$, which may not be parallel to each other. Specifically, $U_{i}$ is expressed as $U_{i}=(1 / 2) \cdot \rho_{\text {water }} \cdot g$. $\left(h_{i-1}+h_{i}\right) \cdot x_{i} \cdot \sec \alpha_{i}$, and $S_{i}=c \cdot x_{i} \cdot \sec \alpha_{i}+P_{i}^{\prime} \cdot \tan \phi$. For matching $Z_{i}, Z_{i-1}$ is decomposed into two components (i.e., $Z_{i-1}^{\prime}$ parallel to $Z_{i}$ and $Z_{i-1}^{\prime \prime}$ parallel to $W_{i}$ ), which are derived as $Z_{i-1}^{\prime}=Z_{i-1} \cdot \cos \theta / \cos \theta^{\prime}$ and $Z_{i-1}^{\prime \prime}=Z_{i-1} \cdot \sin \left(\theta^{\prime}-\theta\right) /$ $\cos \theta^{\prime}$, respectively.

For equilibrium, these forces form a force polygon (Figure 3(b)). Particularly, a generalised interslice resultant expressed as $Q_{i}=Z_{i}-Z_{i-1}^{\prime}$ is adopted for analysis. By resolving normal and parallel to the slice base for these forces, three expressions for $Q_{i}$ are obtained for three kinds of slices that are classified as follows:

(i) For slice.1, $Z_{i-1}$ is the hydrostatic pressure expressed as $Z_{0}=(1 / 2) \cdot \rho_{\text {water }} \cdot g \cdot h_{0}^{2}$ (Figure $2(\mathrm{~b})$ ). So the slope $\theta$ of $Z_{0}$ in Figure 3 equals zero, and the slope $\theta^{\prime}$ of the interslice force $Z_{1}$ is $\theta_{1}$ (stipulation (a)). $Q_{1}$ is derived as

$$
Q_{1}=\frac{\left(c \cdot x_{1} / F\right) \cdot \sec \alpha_{1}+(\tan \phi / F) \cdot\left[\left(W_{1}+Z_{0} \cdot \tan \theta_{1}\right) \cdot \cos \alpha_{1}-U_{1}\right]-\left(W_{1}+Z_{0} \cdot \tan \theta_{1}\right) \cdot \sin \alpha_{1}}{\cos \left(\alpha_{1}-\theta_{1}\right) \cdot\left[1+(\tan \phi / F) \cdot \tan \left(\alpha_{1}-\theta_{1}\right)\right]} .
$$




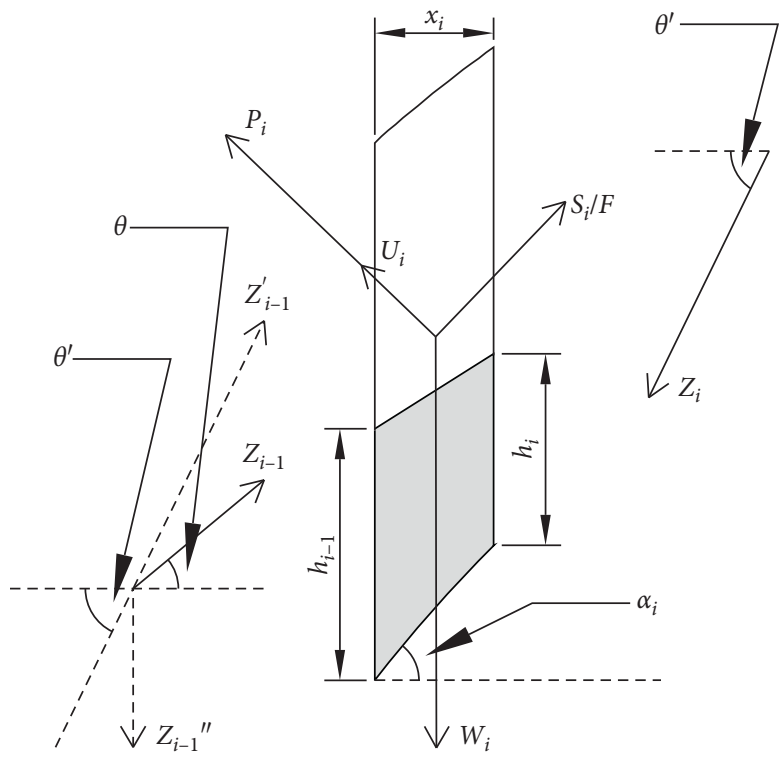

(a)

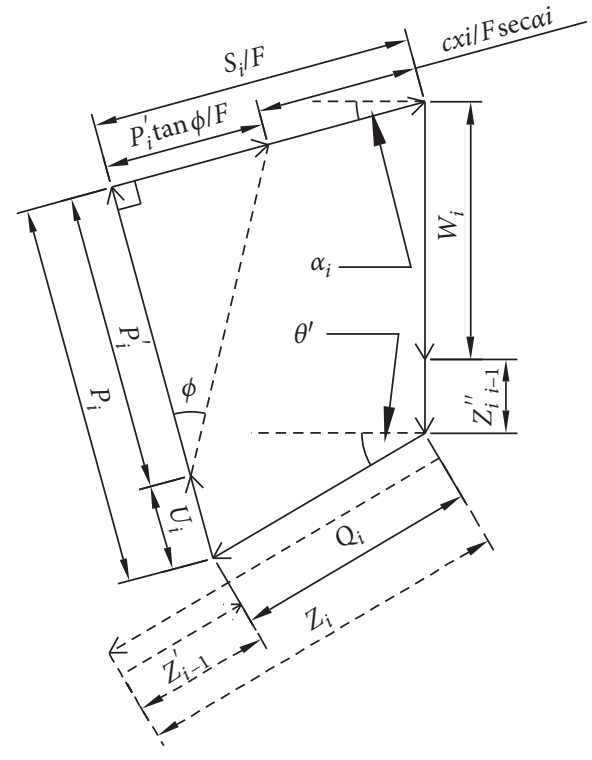

(b)

FIgURE 3: (a) Force analysis of slice.i. (b) Force polygon of slice.i.

(ii) For the first slice in circle. $m(m \neq 1), Z_{i-1}$ is the "linkforce" (such as $Z_{a}$ in Figure 2(b)). So the slope $\theta$ of $Z_{i-1}$ is $\theta_{m-1}$, and the slope $\theta^{\prime}$ of the interslice force $Z_{i}$ is $\theta_{m}$ (stipulations (a) and (b)). $Q_{i}$ in this case is therefore

$$
Q_{i}=\frac{\left(c \cdot x_{i} / F\right) \cdot \sec \alpha_{i}+(\tan \phi / F) \cdot\left[\left(W_{i}+Z_{i-1}^{\prime \prime}\right) \cdot \cos \alpha_{i}-U_{i}\right]-\left(W_{i}+Z_{i-1}^{\prime \prime}\right) \cdot \sin \alpha_{i}}{\cos \left(\alpha_{i}-\theta_{m}\right) \cdot\left[1+(\tan \phi / F) \cdot \tan \left(\alpha_{i}-\theta_{m}\right)\right]} .
$$

(iii) For any other slice except the above two cases, the interslice forces $\left(Z_{i-1}\right.$ and $\left.Z_{i}\right)$ are parallel, so the slopes $\left(\theta\right.$ and $\left.\theta^{\prime}\right)$ of them both equal $\theta_{m}$ (stipulation (a)). Thus, $Q_{i}$ is

$Q_{i}=\frac{\left(c \cdot x_{i} / F\right) \cdot \sec \alpha_{i}+(\tan \phi / F) \cdot\left(W_{i} \cos \alpha_{i}-U_{i}\right)-W_{i} \cdot \sin \alpha_{i}}{\cos \left(\alpha_{i}-\theta_{m}\right) \cdot\left[1+(\tan \phi / F) \cdot \tan \left(\alpha_{i}-\theta_{m}\right)\right]}$.

In order to determine the FoS, global equilibrium for each circle is analysed in turn with the following steps.
Step 1: For circle.1, by projecting all the forces acting on the slices onto the direction of $\theta_{1}$ for balance, the force equilibrium equation is obtained:

$\sum_{i=1}^{a} Q_{i}+Z_{0}^{\prime}-Z_{1}+Z_{1}-\cdots-Z_{a-1}+Z_{a-1}-Z_{a}=0 \Longrightarrow Z_{a}=\sum_{i=1}^{a} Q_{i}+Z_{0}^{\prime}$.

Furthermore, by taking the moments of all these forces about the rotation centre $O_{1}$ for balance, the moment equilibrium equation is obtained:

$$
\begin{gathered}
\sum_{i=1}^{a} Q_{i} \cdot \cos \left(\alpha_{i}-\theta_{1}\right)+Z_{0}^{\prime} \cdot \cos \left(\alpha_{1}-\theta_{1}\right)-Z_{1} \cdot \cos \left(\alpha_{1}-\theta_{1}\right)+Z_{1} \cdot \cos \left(\alpha_{2}-\theta_{1}\right) \\
-\cdots-Z_{a-1} \cdot \cos \left(\alpha_{a-1}-\theta_{1}\right)+Z_{a-1} \cdot \cos \left(\alpha_{a}-\theta_{1}\right)-Z_{a} \cdot \cos \left(\alpha_{a}-\theta_{1}\right)=0
\end{gathered}
$$

If the circle is sliced more finely, it is judged that

$$
\lim _{x_{i} \longrightarrow 0} \alpha_{1} \approx \alpha_{2}, \lim _{x_{i} \longrightarrow 0} \alpha_{2} \approx \alpha_{3}, \ldots, \lim _{x_{i} \longrightarrow 0} \alpha_{a-1} \approx \alpha_{a} .
$$

Thus, equation (5) is transformed into the following equation:

$$
\text { Equation }(5) \Rightarrow \sum_{i=1}^{a} Q_{i} \cdot \cos \left(\alpha_{i}-\theta_{1}\right)=Z_{a} \cdot \cos \left(\alpha_{a}-\theta_{1}\right)-Z_{0}^{\prime} \cdot \cos \left(\alpha_{1}-\theta_{1}\right)
$$


Because $Z_{a}$ is a variable, it should be removed by substituting equation (4) into equation (7), so that a comprehensive equilibrium equation containing two variables $\left(F\right.$ and $\left.\theta_{1}\right)$ is obtained:

$$
\sum_{i=1}^{\mathrm{a}} Q_{i} \cdot \cos \left(\alpha_{i}-\theta_{1}\right)=\left(\sum_{i=1}^{\mathrm{a}} Q_{i}\right) \cdot \cos \left(\alpha_{\mathrm{a}}-\theta_{1}\right)+Z_{0}^{\prime} \cdot\left[\cos \left(\alpha_{\mathrm{a}}-\theta_{1}\right)-\cos \left(\alpha_{1}-\theta_{1}\right)\right]
$$

Giving $F$ an initial value $F_{0}, \theta_{1}$ within equation (8) can be determined as $\left(\theta_{1}\right)_{F_{0}}$. Then, by substituting $F_{0}$ and $\left(\theta_{1}\right)_{\mathrm{F}_{0}}$ back into equation (4), $Z_{a}$ is determined as $\left(Z_{a}\right)_{F_{0}}$.

Step .2: For circle.2, $\left(\theta_{1}\right)_{F_{0}}$ and $\left(Z_{a}\right)_{F_{0}}$ obtained by Step 1 are treated as known quantities. Similarly, the force and moment equilibrium equations for this circle are obtained as follows:

$$
Z_{b}=\sum_{i=a+1}^{b} Q_{i}+\left(Z_{a}\right)_{F_{0}}^{\prime}
$$

$$
\begin{aligned}
\sum_{i=a+1}^{b} Q_{i} \cdot \cos \left(\alpha_{i}-\theta_{2}\right)= & Z_{b} \cdot \cos \left(\alpha_{b}-\theta_{2}\right)-\left(Z_{a}\right)_{F_{0}}{ }^{\prime} \\
& \cdot \cos \left(\alpha_{a+1}-\theta_{2}\right)
\end{aligned}
$$

where $Z_{b}$ is a variable, so it is removed by substituting equation (9) into equation (10) to obtain a comprehensive equilibrium equation:

$$
\begin{aligned}
\sum_{i=a+1}^{b} Q_{i} \cdot \cos \left(\alpha_{i}-\theta_{2}\right)= & \left(\sum_{i=a+1}^{b} Q_{i}\right) \cdot \cos \left(\alpha_{b}-\theta_{2}\right)+\left(Z_{a}\right)_{F_{0}}^{\prime} \\
& \cdot\left[\cos \left(\alpha_{b}-\theta_{2}\right)-\cos \left(\alpha_{a+1}-\theta_{2}\right)\right] .
\end{aligned}
$$

Because $F$ being set as $F_{0}$ is the same for all the circles, the only variable $\theta_{2}$ in equation (11) can be determined as $\left(\theta_{2}\right)_{F_{0}}$. In turn, by substituting $F_{0}$ and $\left(\theta_{2}\right)_{F_{0}}$ back into equation (9), $Z_{b}$ is determined as $\left(Z_{b}\right)_{F_{0}}$.

Step 3 n: Following the order of $m$, circle. 3 to circle. $n$ is analysed successively. As for Step 2, a key operation herein is that $\left(\theta_{m-1}\right)_{F_{0}}$ and $\left(Z_{a / b / c \ldots}\right)_{F_{0}}$ obtained in circle. $m-1$ should be treated as known quantities in circle. $m$ that is being analysed. In this way, the variables $\left(\theta_{m}, Z_{a / b / c . . .}\right)$ relying on $F_{0}$ for all the circles can be solved in turn, including $\left(Z_{q}\right)_{F_{0}}$ for the last slice. $q$ (Figure 2(a)).
Step $n+1$ : Considering the boundary conditions, it should be verified whether $\left(Z_{q}\right)_{F_{0}}$ obtained in Step $n$ equals zero. If $\left(Z_{q}\right)_{F_{0}} \neq 0$, then the value of $\mathrm{F}_{0}$ should be adjusted accordingly for repeating Step 1 to Step $n+1$ in turn, until a final $F_{0}$ is found for the FoS that makes $\left(Z_{q}\right)_{F_{0}} \approx 0$.

2.2. Extension of the Method to the Study of DDF. Figure 4 shows an example of a slope reinforced with a row of piles, where the piles are located at the intersection of circle. 1 and circle. 2 . With the pile as a boundary, the sliding mass is divided into two portions, that is, the sliding body in front of the pile and the sliding body behind the pile. The function of the pile is to bear the sliding thrust $\left(N_{2}\right)$ transmitted from the sliding body behind and to transmit a part of it $\left(N_{1}\right)$ to the sliding body in front (see Figure 4), so that the FoS of these two bodies can be simultaneously increased to the safety coefficient $\left(F_{s}\right)$ that is a constant prescribed for guaranteeing the desired safety of the slope $[22,25]$. Thus, the net thrust $N$ acting on the pile is obtained as $N=N_{2}-N_{1}$, which is defined as the DDF to be calculated $[26,27]$.

Two portions are considered separately for determining the sliding thrust $N_{2}$ and the resisting force $N_{1}$.

Portion I $\left(N_{2}\right)$ : If the sliding body behind the pile should be in a specified safety state $\left(F_{s}\right)$, it will transmit thrust $N_{2}$ to the pile. In turn, the pile will react with an equal $N_{2}$ (Figure 4). Thus, the force diagram for slice. $a+1$ is redrawn in Figure 5(a), where the slope of $N_{2}$ is $\psi$ and the inclination of $Z_{a+1}$ is $\theta_{2} . N_{2}$ is then decomposed into two components as shown in Figure 5(a), which are derived as $N_{2}^{\prime}=N_{2} \cdot \cos \psi /$ $\cos \theta_{2}$ and $N_{2}^{\prime \prime}=N_{2} \cdot \sin \left(\theta_{2}-\psi\right) / \cos \theta_{2}$, respectively. Based on a similar force polygon to Figure $3(\mathrm{~b}), Q_{a+1}$ is derived as

$$
Q_{a+1}=\frac{\left(c \cdot x_{a+1} / F_{s}\right) \cdot \sec \alpha_{a+1}+\left(\tan \phi / F_{s}\right) \cdot\left[\left(W_{a+1}+N_{2}^{\prime \prime}\right) \cdot \cos \alpha_{a+1}-U_{a+1}\right]-\left(W_{a+1}+N_{2}^{\prime \prime}\right) \cdot \sin \alpha_{a+1}}{\cos \left(\alpha_{a+1}-\theta_{2}\right) \cdot\left[1+\left(\tan \phi / F_{s}\right) \cdot \tan \left(\alpha_{a+1}-\theta_{2}\right)\right]}
$$

For any other slice, $Q_{i}$ is still derived from equation (2) or (3), but the variable $F$ in the equations should be replaced by $F_{s}$.
In order to determine the value of $N_{2}$, force and moment equilibrium equations for each circle $(2 \sim n)$ should be established in turn in the same way as 


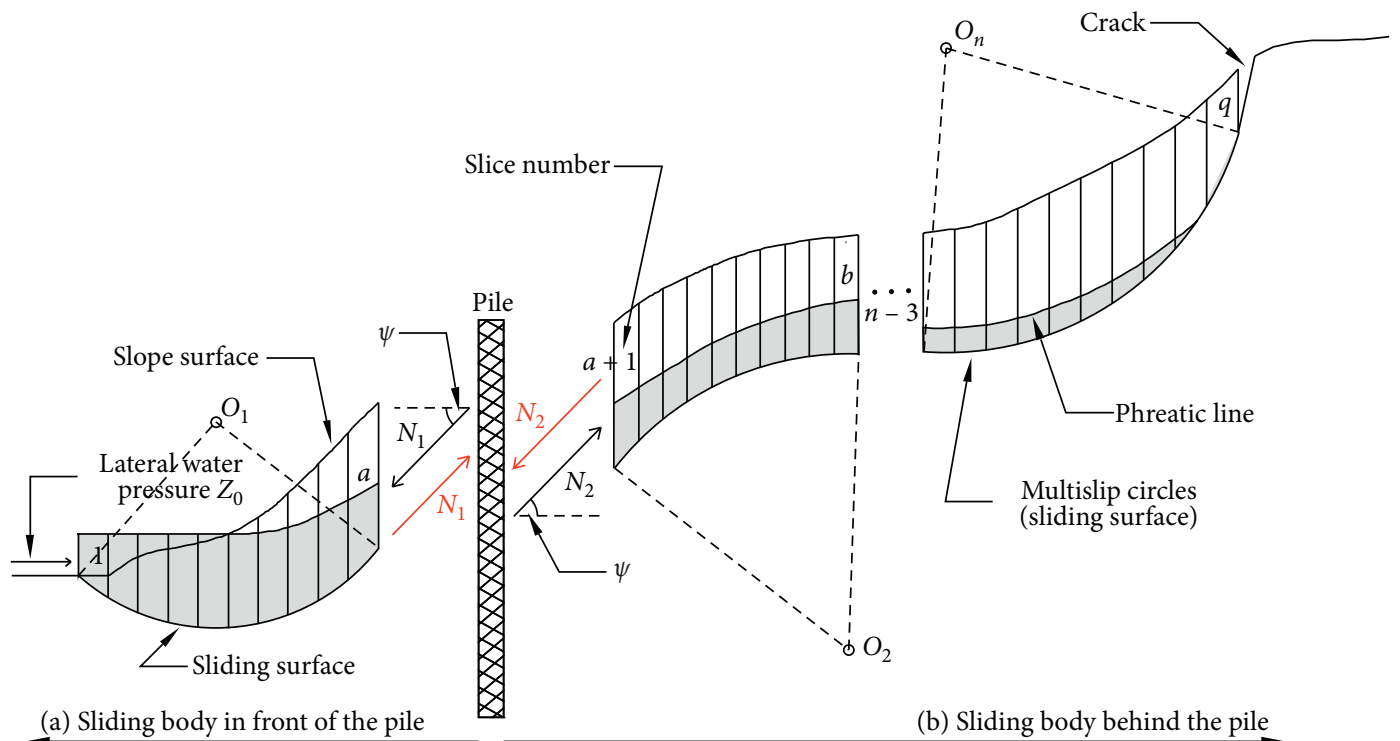

FIgURE 4: Planar model of a slope reinforced with a row of piles.

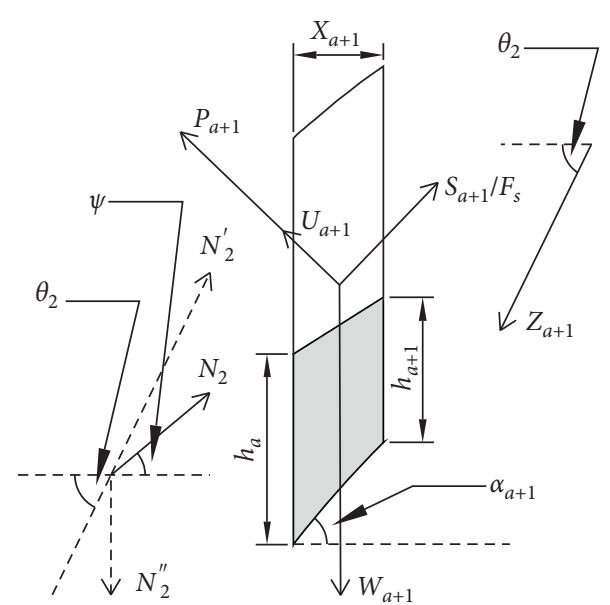

(a)

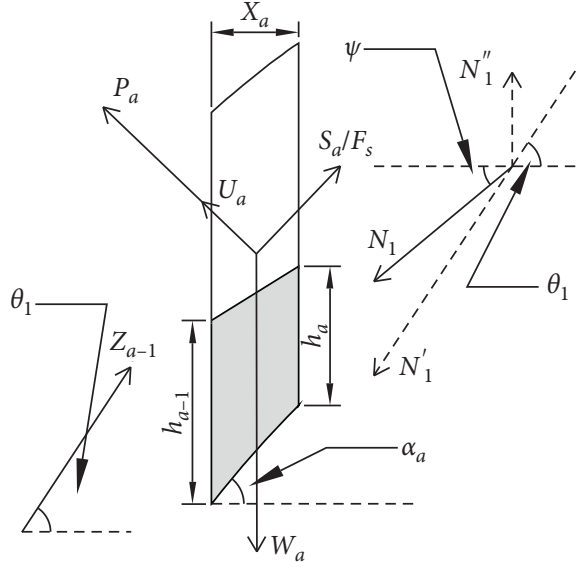

(b)

Figure 5: Force diagram of the slice. (a) Slice. $a+1$. (b) Slice. $a$.

described above, and a total of $(2 n-2)$ equations can be obtained. Because $F$ is set as $\mathrm{F}_{s}$, a total of $(2 n-1)$ variables exist in all the equations which are $N_{2}$, $\theta_{2} \sim \theta_{n}$, and the "link-forces" $Z_{b} \sim Z_{q}$. One boundary condition is that $Z_{q}$ equals zero, so the problem is statically determinate. $N_{2}$ can be solved by a trial-anderror procedure until a final one is found which satisfies all the mechanical conditions.

Portion II $\left(N_{1}\right)$ : the sliding body in front of the pile usually acts as a "resisting section" such that it can share a small part of the thrust $N_{1}$ transmitted from the pile.
In turn, an equal resisting force $N_{1}$ from that body will act on the pile (Figure 4). The key question is how large is the value of $N_{1}$ that can make the FoS of this section also equal $F_{s}$. The force diagram for slice. $a$ is redrawn in Figure 5(b), where the slope of $N_{1}$ is $\psi$ and the inclination of $Z_{a-1}$ is $\theta_{1}$. Similarly, $N_{1}$ is decomposed into two components, which are $N_{1}^{\prime}=N_{1} \cdot \cos \psi / \cos \theta_{1}$ and $N_{1}^{\prime \prime}=-N_{1} \cdot \sin \left(\theta_{1}-\psi\right) / \cos \theta_{1}$, respectively. Thus, $Q_{a}$ is derived as

$$
Q_{a}=N_{1}^{\prime}-Z_{a-1}=\frac{\left(c \cdot x_{a} / F_{s}\right) \cdot \sec \alpha_{a}+\left(\tan \phi / F_{s}\right) \cdot\left[\left(W_{a}+N_{1}^{\prime \prime}\right) \cdot \cos \alpha_{a}-U_{a}\right]-\left(W_{a}+N_{1}^{\prime \prime}\right) \cdot \sin \alpha_{a}}{\cos \left(\alpha_{a}-\theta_{1}\right) \cdot\left[1+\left(\tan \phi / F_{s}\right) \cdot \tan \left(\alpha_{a}-\theta_{1}\right)\right]}
$$


For other slices, $Q_{1}$ is derived from equation (1) and the other $Q_{i}$ are from equation (3); also the variable $F$ within them should be replaced by $F_{s}$.

As $N_{2}$, the problem of solving $N_{1}$ is statically determinate because $F_{s}$ and $Z_{0}$ are known quantities, so its solution procedures are similar to those described for Portion I. Notably, the analysis process is also similar if there is more than one circle in front of the pile.

It is noted that the calculation order described above is from the toe to the crest, but it can also be conducted from the crest to the toe. If so, stipulation (b) and the analysis procedures should be both reversed. These two orders corresponding to "new method-1" and "new method-2," respectively, are both adopted and verified in the following cases, from which small differences between them are still found, although their mechanical principles are the same. In this paper, all the calculation procedures were programmed by MATLAB 7.0.

\section{Case Studies}

The following two typical colluvial landslides located in the TGR area of China were used as case studies.

Case 1. The Jinle 2\# landslide plotted in Figure 6(a) is located on the left bank of the Xiangxi River (a branch of the Yangtze River) (Figure 6(b)), where the bedrocks exposed are interbedded layers of Jurassic (J2x) pelitic siltstone and mudstone, presenting a monoclinal geological structure; see Figure 7. Geological survey by boreholes reveals that the sliding surface/zone exhibits a stepped/multicircular shape $[23,28]$, and the overlying sliding mass is predominantly composed of colluvium-diluvium and eluvium. The basic physical parameters of the materials are obtained from soil mechanics tests (Table 1). For establishing the analysis model for the new method, seven slip-circles (arcs) were constructed to fit the natural sliding surface. Then, the analysis of FoS and the DDF was conducted for the case that the slope toe is above the reservoir water level (135 $\mathrm{m}$ asl).

Case 2. The Huangtupo 1\# slump-mass is located on the right bank of the Yangtze River, west of the Jinle landslide (see Figures 6(a) and 6(c)). A series of geological surveys (including drilling holes, testing tunnels, and sliding surfaces displacement monitoring) carried out by China University of Geosciences reveal that there are actually two separate sliding surfaces/zones of different depth controlling the landslide $[29,30]$, where the deep-seated one is generated along the weathered Triassic strata of the Badong Formation $\left(T_{2} B^{3}\right)$ but the shallow one is formed by the second slide that occurred within the overlying landslide mass (Figures 6(c) and 8). The testing tunnel passes through the shallow sliding surface (shown in Figure 9), and a circular shape of the local sliding surface is exposed, which further verifies that the shape of this potential sliding surfaces is characterized by circles. As a result, the landslide is divided into four portions from slope surface to the bedrocks, which are, respectively, the shallow slip-mass, shallow slip-zone, deep-seated slipmass, and deep-seated slip-zone [23, 31]. The mechanical parameters of these were collated from experimental data (Table 2). The FoS of the two slides in this case were then studied by adopting two four-circle models that fit well the natural sliding surfaces/zones; for brevity, the study of the DDF is not repeated.

3.1. Study of the FoS. The results of iterations of the new method-1 and method-2 for the two cases are shown in Figure 10, where the value of $Z_{q}$ is successively varying with the variable $F_{0}$. The FoS for each case is determined by searching the valid $F_{0}$ that makes $Z_{q}$ equal zero.

Furthermore, several traditional methods together with the Finite Element (FE) method classified in Table 3 were employed to make comparisons with the new method. Three indexes, the FoS, the normal stresses on slice bases, and the interslice forces calculated by the above methods for each case, are compared in Table 4 and Figure 11, respectively. Note that the discretized FE models corresponding to the two real cases are presented in Figures 12 and 13, respectively, in which the landslides are meshed in the form of quadrilateral and triangular meshes, and, especially near the sliding zones, the meshes are designed more finely.

The comparisons show the following:

(i) The new method gives acceptable results and is close to Spencer's method, at least for these two real cases.

(ii) Although there is little difference between new method-1 and method-2, the former is a little more conservative than the latter.

(iii) The forces calculated by different methods show similar distributions. Although slight distinctions exist for the normal stresses, little influence has been found on the accuracy of FoS and the interslice forces.

(iv) The interslice forces for these cases are positive, which reflect the squeezing actions between the circles. That means the retrogressive failure is at least not existing for these cases, so the assumption of the same FoS for the entire rigid sliding mass is valid.

3.2. Study of the DDF. The Jinle 2\# landslide was taken as an example, where six different positions of a single row of piles seated at the intersections of every two arcs were selected for this study (Figure 7), with the value of $F_{s}$ being specified as 1.35. Because the deformation of the pile is mainly controlled by the horizontal component of the driving force [32], it is considered that selecting the value of $\psi$ as zero for the following study is of practical significance.

The sliding thrusts $\left(N_{2}\right)$ and the resisting forces $\left(N_{1}\right)$ calculated by different methods at each pile's position are shown in Figures 14(a) and 14(b), respectively. The Bishop method cannot be used for calculating the forces, and the results calculated by the Ordinary method are apparently unreliable, so they should be both ignored below. The standard deviation (illustrated in Figure 14) at each pile's 


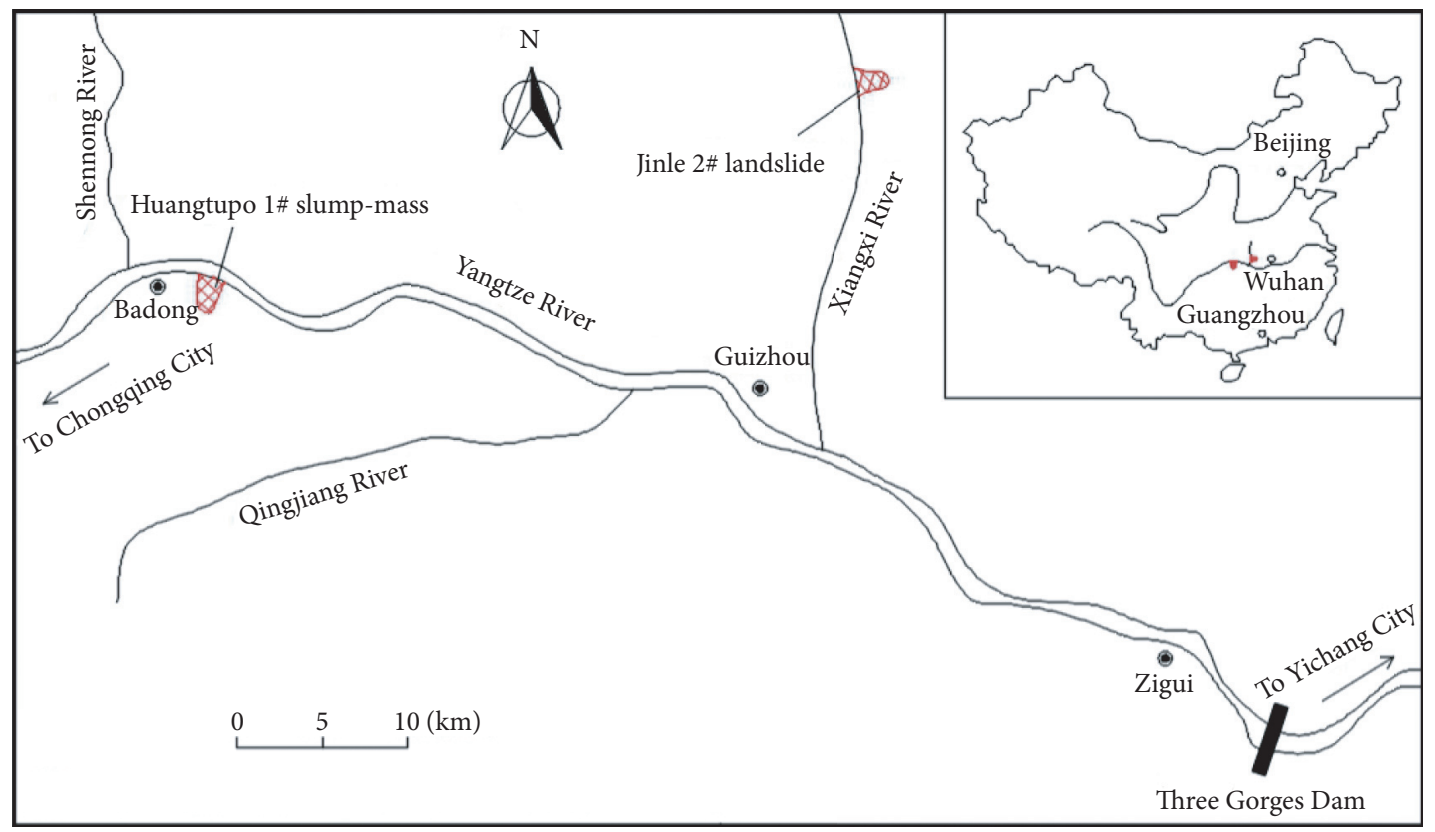

(a)

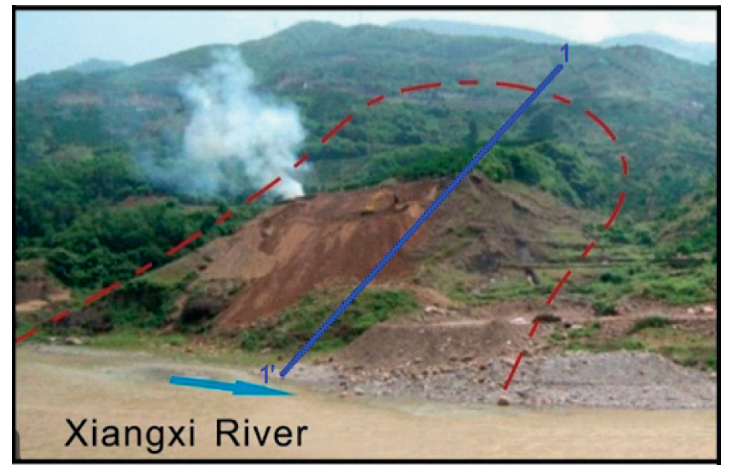

(b)

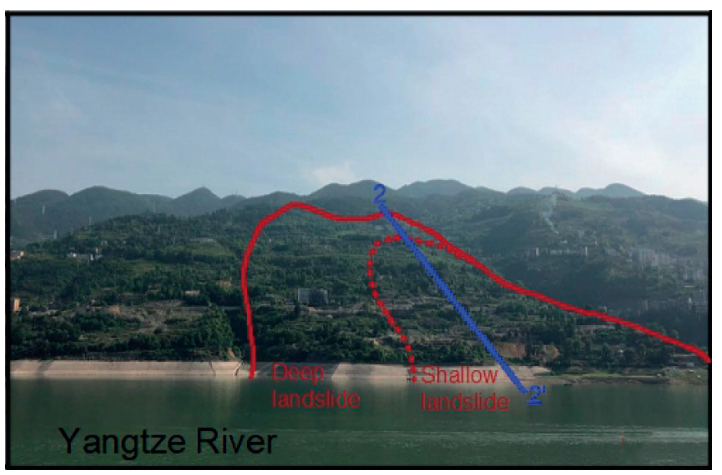

(c)

FIgure 6: (a) Location of the two landslides in the TGR area. (b) Picture of the Jinle 2\# landslide. (c) Picture of the Huangtupo 1\# slumpmass.

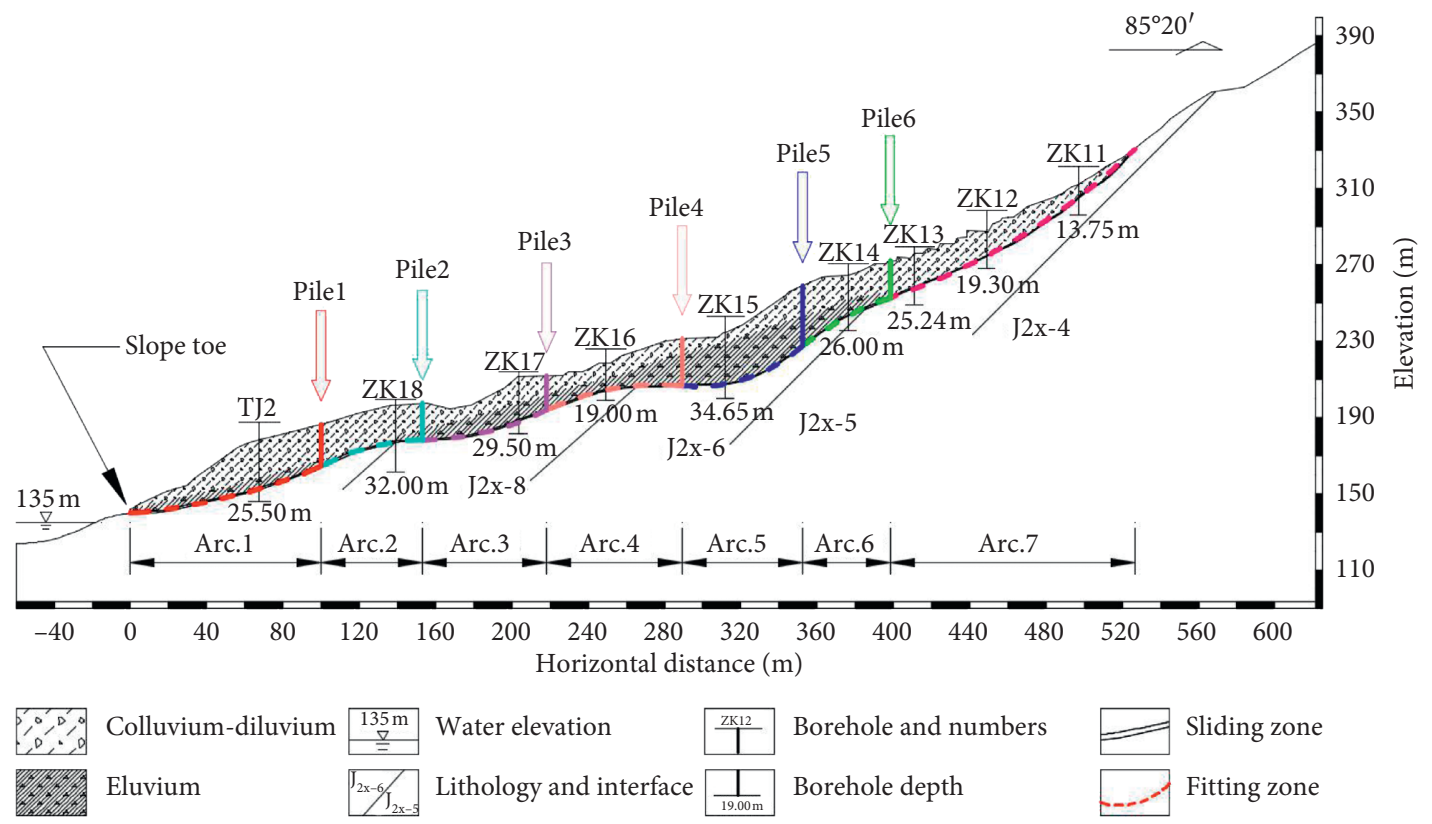

Figure 7: Engineering geological profile of the Jinle 2\# landslide. 
TABle 1: Physical parameters of soils for the Jinle 2\# landslide.

\begin{tabular}{lccc}
\hline Items & Sliding mass & Sliding zone & Bedrocks \\
\hline Friction angle $\left({ }^{\circ}\right)$ & 20.5 & 16.8 & 34 \\
Cohesion $(\mathrm{kPa})$ & 28.6 & 24.5 & 2500 \\
E-modulus $(\mathrm{MPa})$ & 10 & 7.8 & $1.48 \times 10^{4}$ \\
Poisson's ratio & 0.30 & 0.4 & 0.25 \\
Unit weight $\left(\mathrm{kg} / \mathrm{m}^{3}\right)$ & 18.3 & 18.3 & 22.3 \\
\hline
\end{tabular}

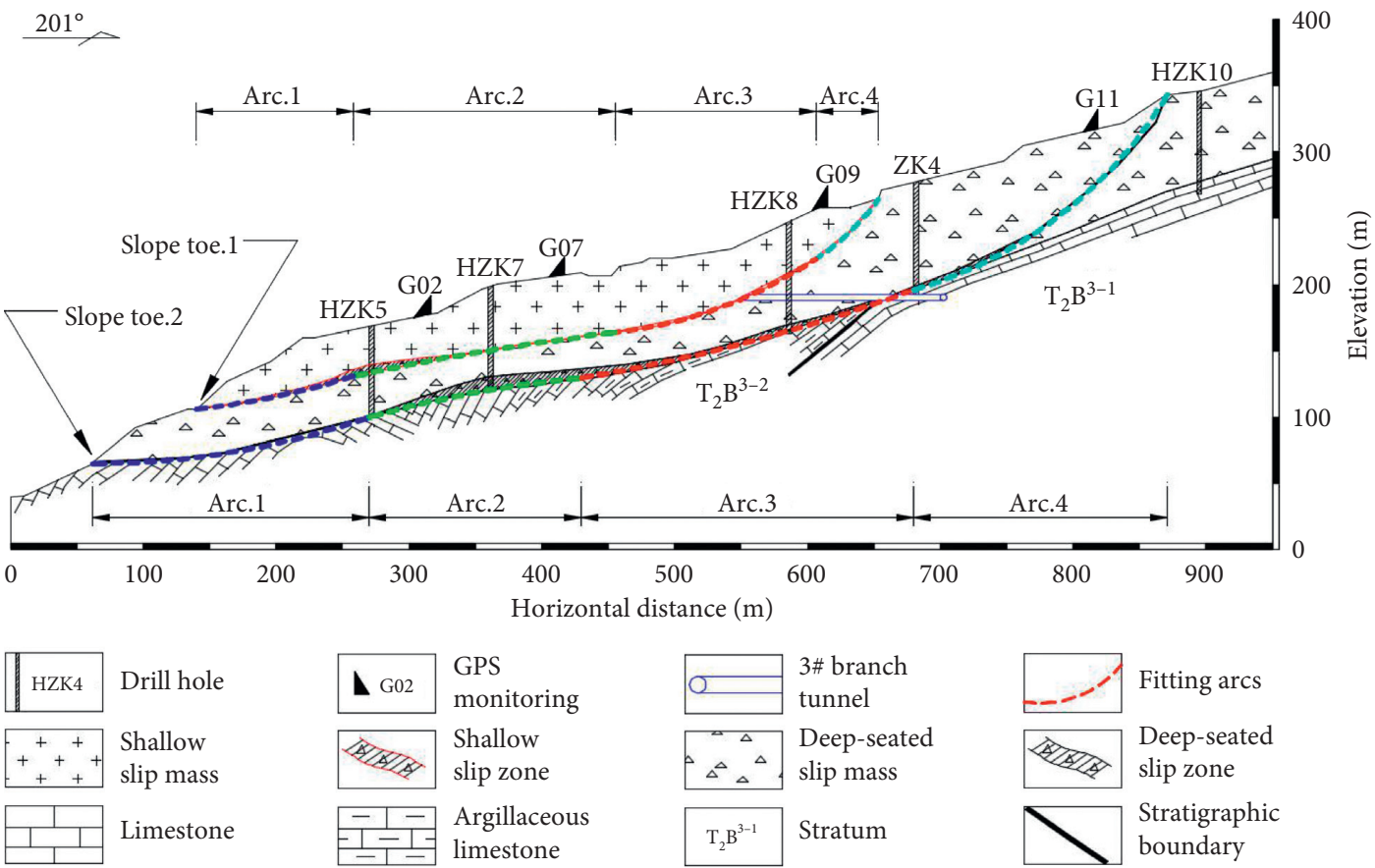

Figure 8: Engineering geological profile of the Huangtupo 1\# slump-mass.

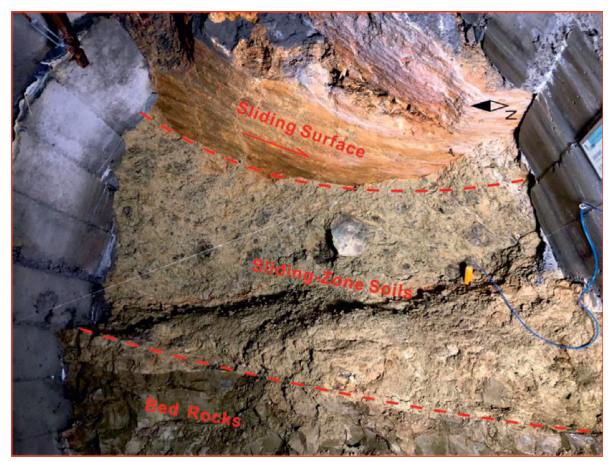

FIgURE 9: Testing tunnel exposing the circular sliding surface of the Huangtupo 1\# slump-mass.

TABLE 2: Physical parameters of soils for the Huangtupo 1\# slump-mass.

\begin{tabular}{lccccc}
\hline Items & Shallow slip-mass & Shallow slip-zone & Deep-seated slip-mass & Deep-seated slip-zone & Bedrocks \\
\hline Friction angle $\left({ }^{\circ}\right)$ & 25 & 14 & 34 & 17.5 & 44.2 \\
Cohesion $(\mathrm{kPa})$ & 80 & 26 & 190 & 32 & 380 \\
E-modulus $(\mathrm{MPa})$ & 727 & 28.6 & 2178 & 36.8 & $3.674 \times 10^{4}$ \\
Poisson's ratio & 0.31 & 0.34 & 0.29 & 26 \\
Unit weight $\left(\mathrm{kg} / \mathrm{m}^{3}\right)$ & 21 & 19.9 & 23 & 21.3 & 0.26 \\
\hline
\end{tabular}




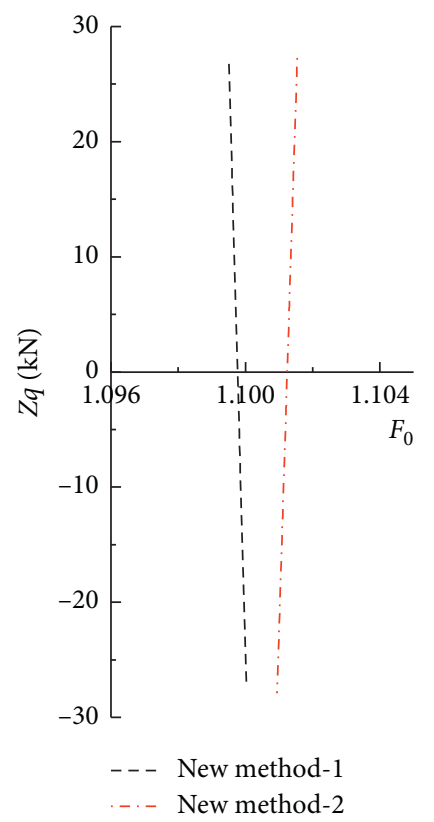

(a)

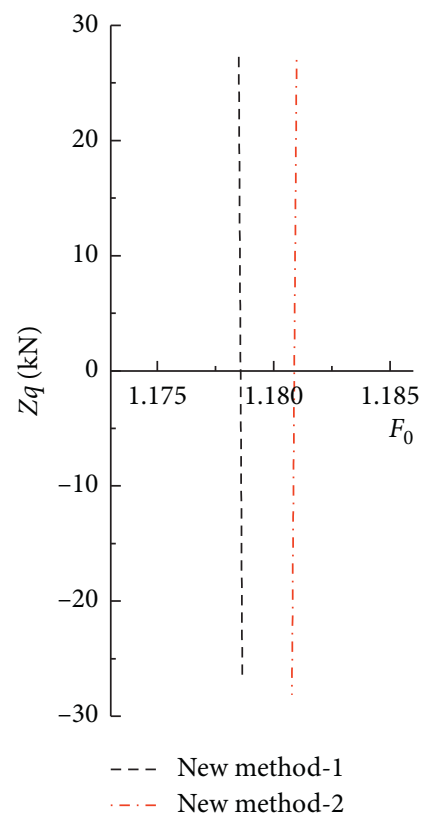

(b)

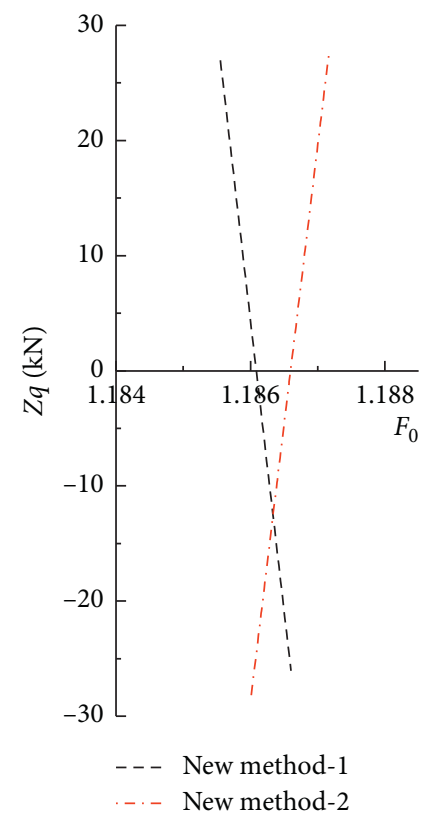

(c)

Figure 10: Variation of $Z_{q}$ with $F_{0}$. (a) Shallow slide of the Huangtupo 1\# slump-mass. (a) Deep-seated slide of the Huangtupo 1\# slumpmass. (c) The Jinle 2\# landslide.

TABLE 3: Statics satisfied and interslice forces in various methods (modified from [10]).

\begin{tabular}{lccccc}
\hline Methods & Moment equilibrium & Force equilibrium & Interslice normal $(E)$ & Interslice shear $(X)$ & Inclination of $X / E$ resultant \\
\hline New method & Yes & Yes & Yes & Yes & Multiple constants \\
RT method & No & Yes & Yes & Yes & Slice base inclination \\
Spencer method & Yes & Yes & Yes & Yes & Single constant \\
M\&P method & Yes & Yes & Yes & Yes & Variable \\
FE method & No & Yes & No & No & Not considered \\
Simplified Janbu & No & Yes & Yes & No & No force \\
Ordinary method & Yes & No & Yes & No & Horizontal \\
Bishop method & Yes & No &
\end{tabular}

Note. These methods are all available in the software of GeoStudio 2007, except the residual thrust method (RT method, [22]) and the new method; the FE method and the Ordinary method do not give the interslice forces; the M\&P method employed below adopts a half-sine function for depicting the inclinations of the interslice forces, and the Spencer method employed is a modified version by Fredlund et al. [19].

TABle 4: Comparison of the FoS calculated by different methods for the real cases.

\begin{tabular}{|c|c|c|c|c|c|c|c|c|}
\hline Case no. & $\begin{array}{c}\text { New method- } \\
1 /-2\end{array}$ & $\begin{array}{c}\mathrm{RT} \\
\text { method }\end{array}$ & $\begin{array}{l}\text { Spencer } \\
\text { method }\end{array}$ & $\begin{array}{l}\text { M\&P } \\
\text { method }\end{array}$ & $\begin{array}{c}\mathrm{FE} \\
\text { method }\end{array}$ & $\begin{array}{l}\text { Simplified } \\
\text { Janbu }\end{array}$ & $\begin{array}{l}\text { Ordinary } \\
\text { method }\end{array}$ & $\begin{array}{l}\text { Bishop } \\
\text { method }\end{array}$ \\
\hline $\begin{array}{l}\text { No. } 1 \text { Jinle 2\# } \\
\text { slide }\end{array}$ & $1.186 / 1.187$ & 1.198 & 1.187 & 1.190 & 1.171 & 1.146 & 1.128 & 1.233 \\
\hline $\begin{array}{l}\text { No. } 2 \text { H-shallow } \\
\text { slide }\end{array}$ & $1.100 / 1.101$ & 1.104 & 1.092 & 1.087 & 1.085 & 1.066 & 1.013 & 1.182 \\
\hline $\begin{array}{l}\text { No. } 2 \text { H-deep } \\
\text { slide }\end{array}$ & $1.179 / 1.181$ & 1.188 & 1.172 & 1.166 & 1.170 & 1.139 & 1.107 & 1.276 \\
\hline
\end{tabular}

position for $N_{2}$ or $N_{1}$ reveals that the difference between $N_{2}$ calculated by different methods will be weakened as the distance from pile's position to the slope toe increases, while this relationship is the reverse for $N_{1}$. This phenomenon demonstrates that the deviation between different methods is positively correlated with the size of sliding mass being analysed.

By subtracting Figure 14(b) from Figure 14(a), Figure $14(\mathrm{c})$ is obtained to show the DDF for each pile's position. For most methods (except the simplified Janbu 


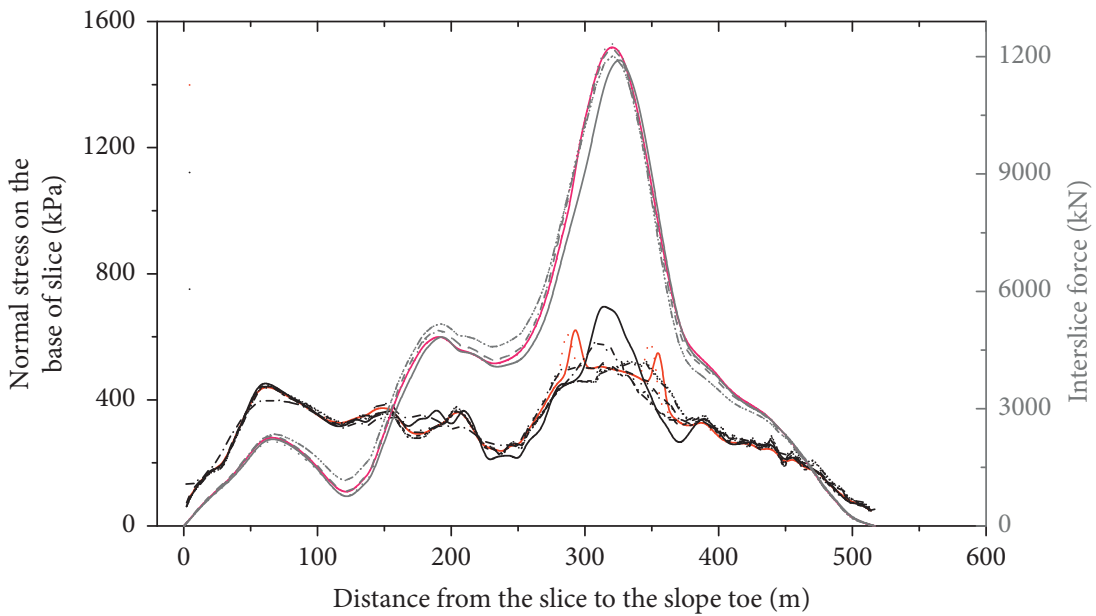

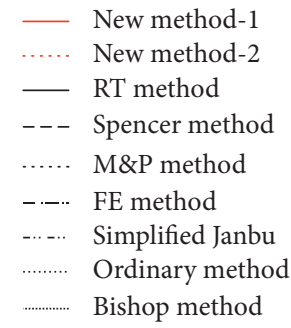

............ Bishop method

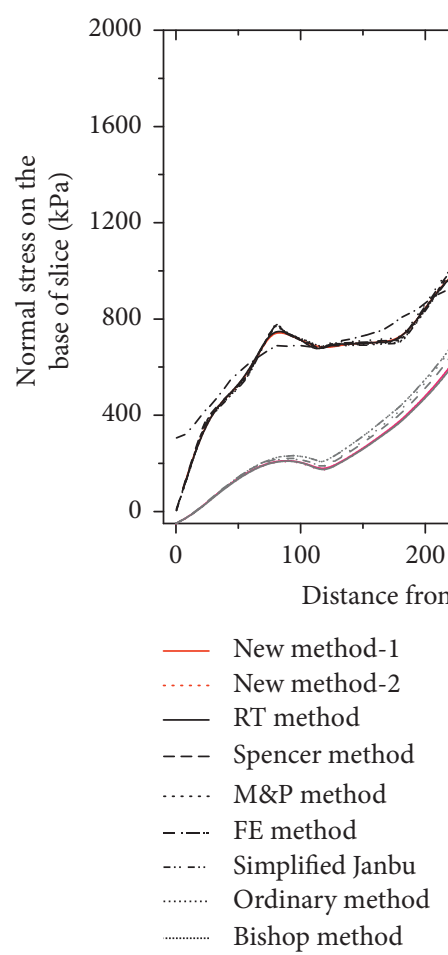

__ New method-1

..... New method-2

- RT method

- - - Spencer method

..... M\&P method

-.-.. FE method

-..... Simplified Janbu

........ Ordinary method

............ Bishop method

(a)

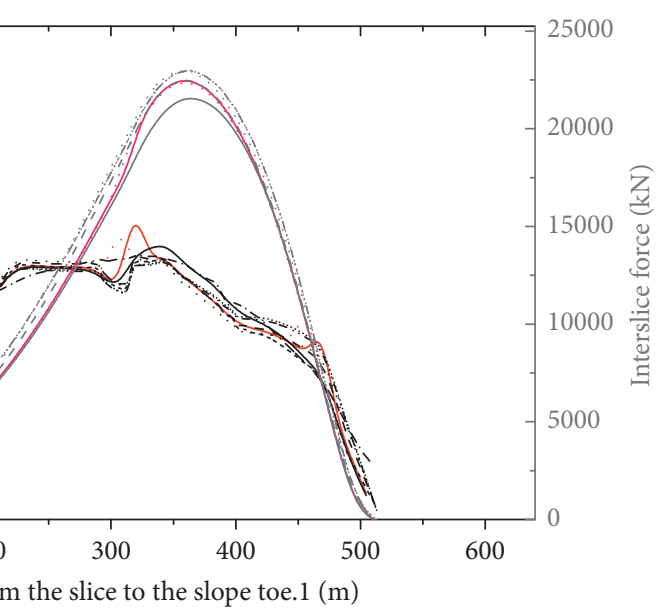

New method-1

..... New method-2

- RT method

--- Spencer method

..... M\&P method

-... FE method

...... Simplified Janbu

........ Ordinary method

......... Bishop method

(b)

FIgURE 11: Continued. 


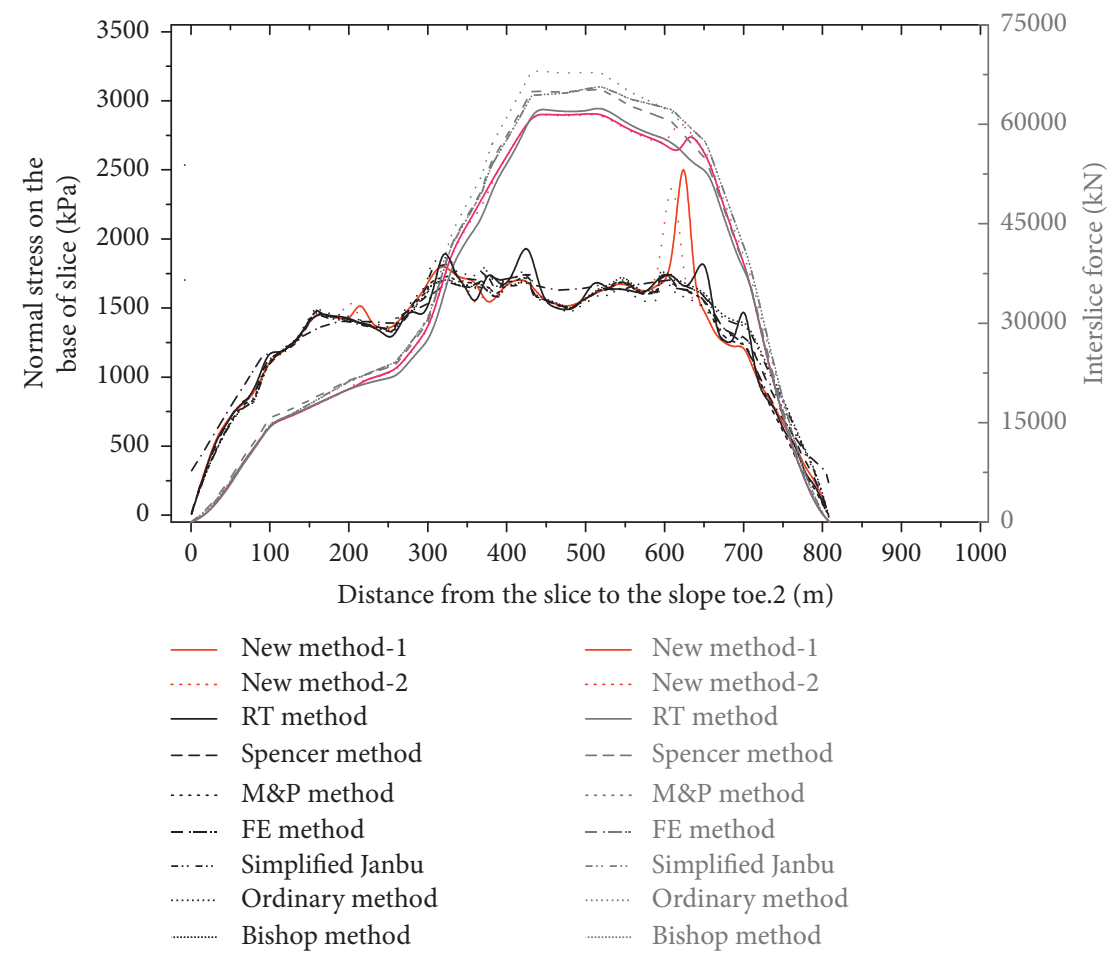

(c)

Figure 11: Forces distribution along the longitudinal direction of the slide. (a) The Jinle 2\# landslide. (b) Shallow slide of the Huangtupo 1\# slump-mass. (c) Deep-seated slide of the Huangtupo 1\# slump-mass.

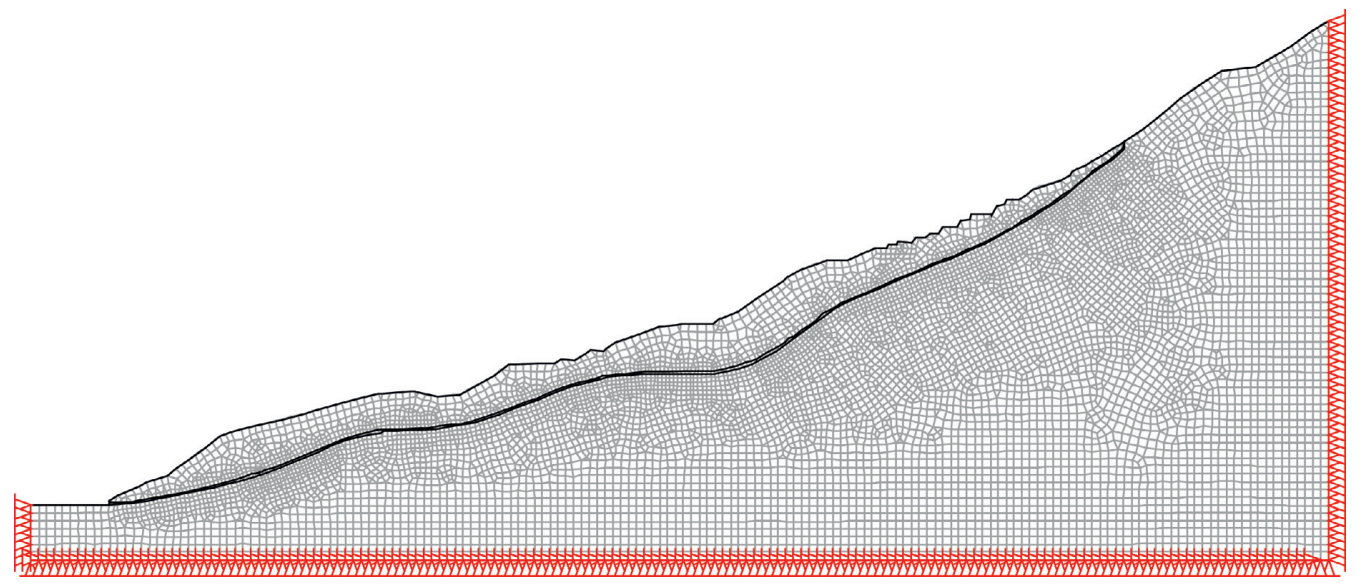

Figure 12: The discretized FE model for the Jinle 2\# landslide (totally with 9006 elements and 8994 nodes).

and the M\&P methods), the DDF on pile.2 and pile.4 shows lower values when compared with those on other piles. This may be attributed to the gentler local sliding surfaces that are around these two piles (see Figure 7) and supports Tan et al.'s standpoint that a gently inclined position of the sliding surface is more suitable for installing stabilising piles [23], from which the extension of the new method for studying the DDF is also proved to be feasible.

\section{Discussion}

For a further understanding of the new method, the following four topics are discussed.

4.1. Factors Influencing the Performance of the Method. As shown in Figure 15, Slope No. 0 was taken as a normal case. Two extra water table lines and slope surfaces are introduced separately for constructing eight extra slope cases 


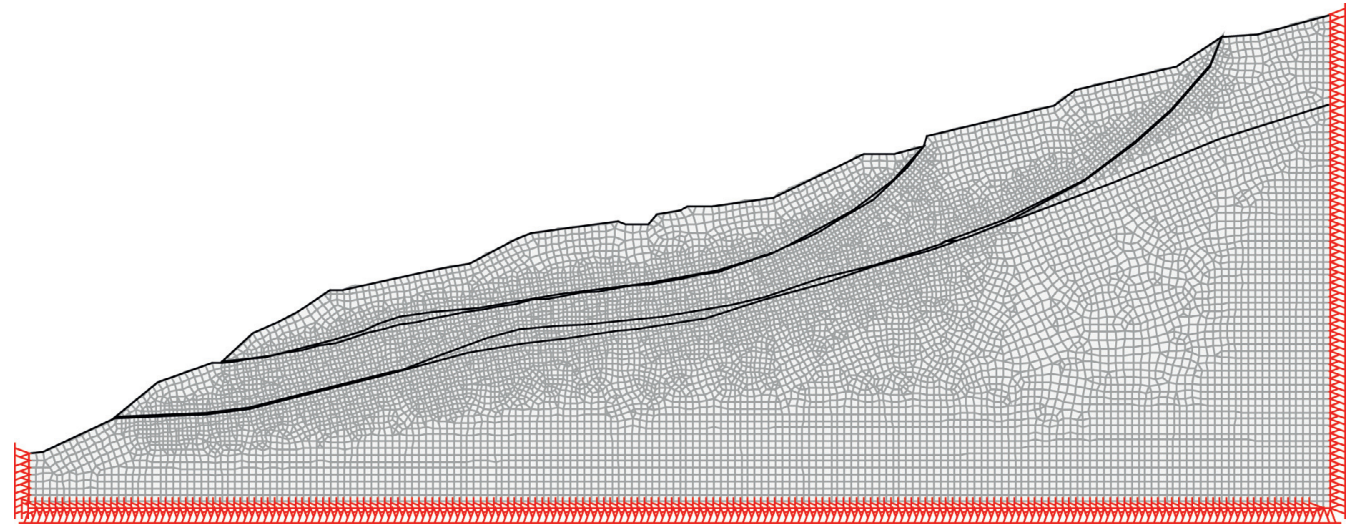

FIGURE 13: The discretized FE model for the Huangtupo 1\# slump-mass (totally with 12537 elements and 12518 nodes).

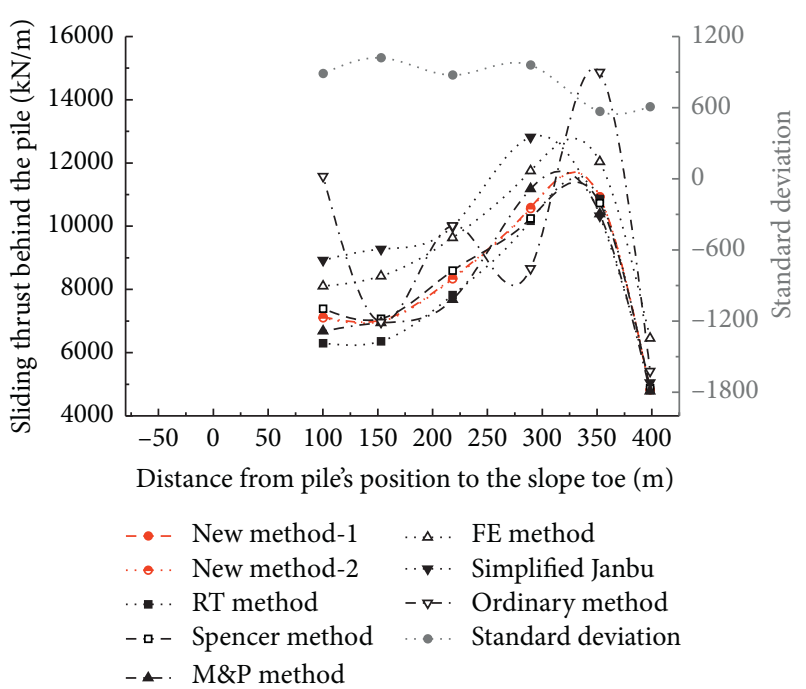

(a)

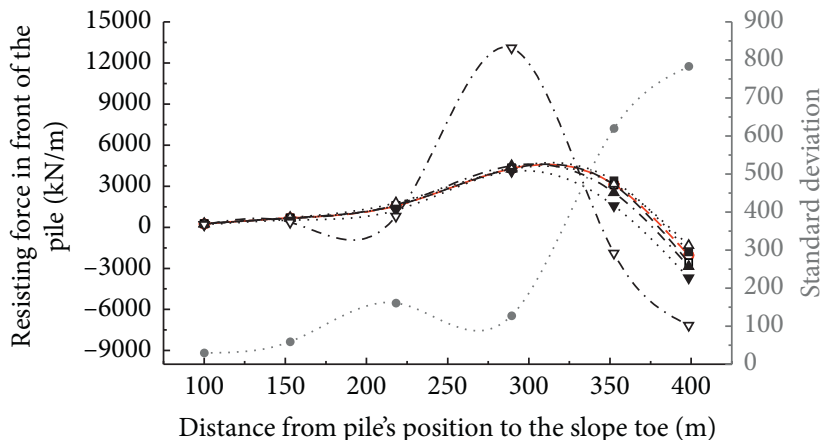

- - New method-1 ..... FE method

-.. New method-2 .... Simplified Janbu

-.. RT method $\quad-\nabla-$. Ordinary method

$-a-$ Spencer method ..... Standard deviation

- ^. M\&P method

(b)

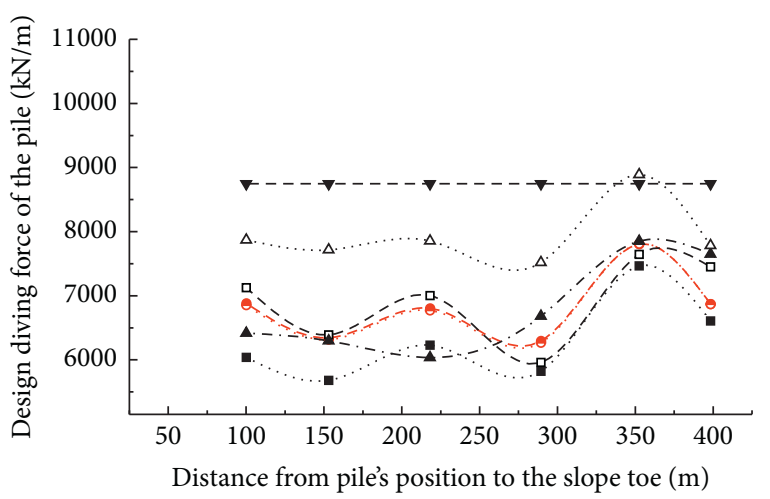

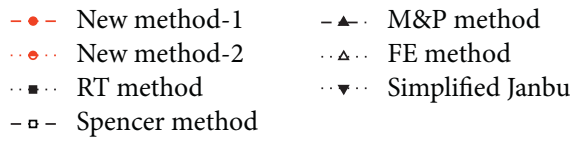

(c)

FIGURE 14: Results calculated by different methods at each pile's position. (a) Sliding thrust $\left(N_{2}\right)$. (b) Resisting force $\left(N_{1}\right)$. (c) DDF $(N)$ on the pile. 


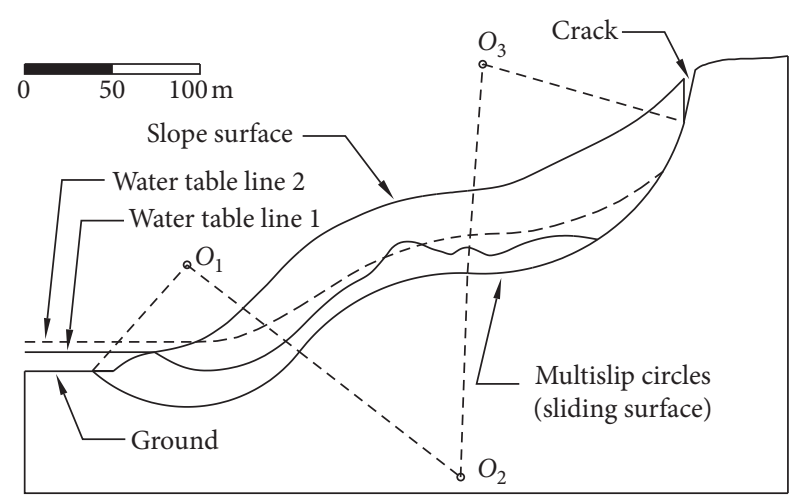

(a)

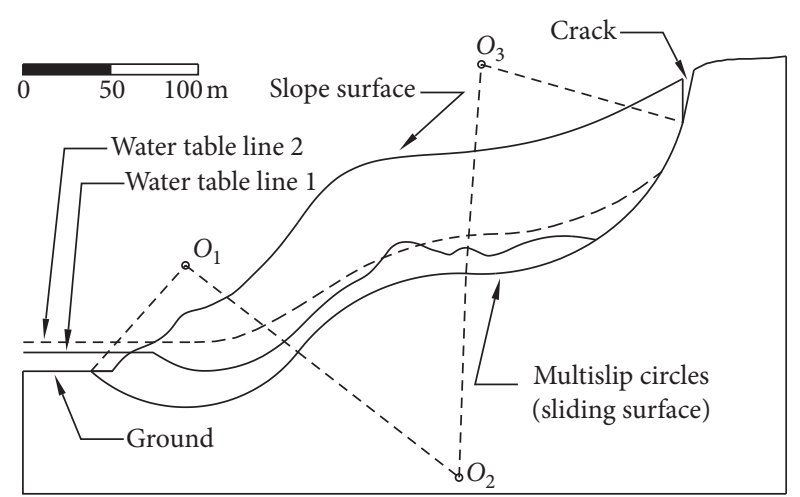

(b)

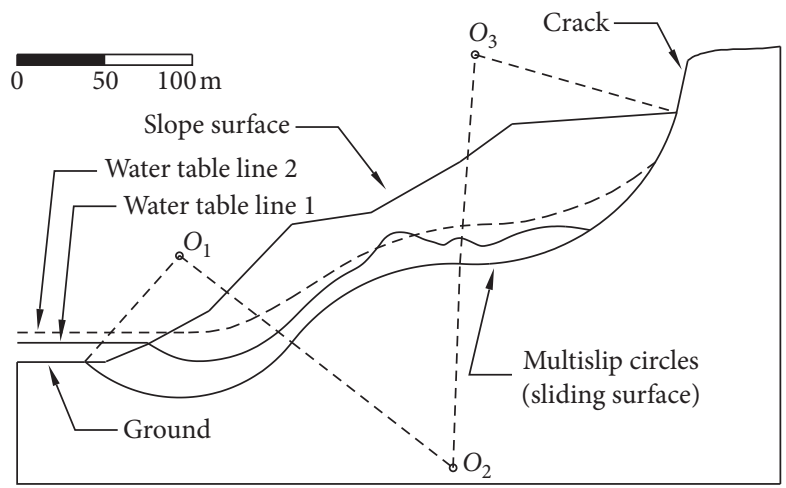

(c)

FIGURE 15: Conceptual slopes with different slope surfaces or water tables. (a) Normal slope surface. (b) Curvilinear slope surface. (c) Polygonal slope surface.

from No. 1 to No. 8, based on which the impact factors of water table and slope surface were studied. In addition, the effect of concavity $\gamma$ of the first slip-circle on the method was also studied with various slip-surfaces from No. -7 to No. 0 , as shown in Figure 16, in which the normal slope surface is shared. To avoid the overlapping influence of factors, the physical parameters for the soil are uniform (Table 5).

The FoS obtained by different methods for each slope are compared in Figure 17(a). The ratios $\left(\mathrm{FoS}_{\mathrm{LEMS}} / \mathrm{FoS}_{\mathrm{FE}}\right)$ of the FoS between LEMS and the FE method for each slope are shown in Figure 17(b). Given that the calculations through the FE method are well accepted, the performance of the new method seems to be much better than the other LEMS. Although the water table and slope surface affect the relative accuracy of the new method, they have little impact on the deviation between the new method and Spencer's method.

Figure 18 presents the difference values of the FoS between LEMS (the new method, Spencer's method, and the M\&P method) and the FE method for Slope No. -7 to No. 0, which are varying with the concavity $\gamma$. It reveals the following: (i) the new method-1 is conservative when compared with new method-2; (ii) the concavity $\gamma$ plays a leading role in influencing the performance of the methods; in particular, the deviations between LEMS and the FE method are decreased to a narrow range as $\gamma$ increases from $-25^{\circ}$ to $-5^{\circ}$; and (iii) if the local sliding surface near the slope toe is concave-upward (i.e., $\gamma>0$ ), the FoS obtained by the new

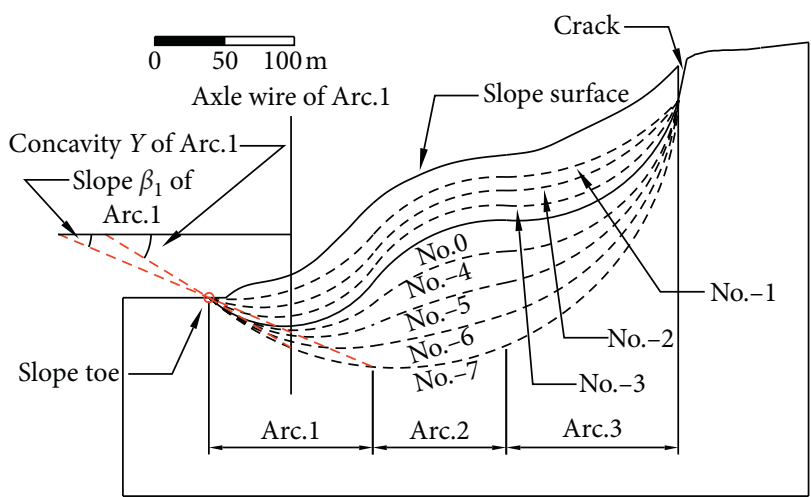

FIgURE 16: Conceptual slopes with different slip-surfaces from No. -7 to No. 0.

method and Spencer's method will be close and even exceed that obtained by the FE method, which has also been verified in the real cases.

4.2. Proximity Between Actual and Ideal Slip-Surfaces. Figure 19 shows that the incomplete alignment between the actual sliding surface and the ideal fitted slip-circle may cause differences between the actual and the fitted slice bases. The actual distance from the base of slice. $i$ to the rotation centre $O$ is $R_{i}^{\prime}$, so the real moment equilibrium equation for 
Table 5: Physical parameters for the slope soil.

\begin{tabular}{lccccc}
\hline Items & Friction angle $\left({ }^{\circ}\right)$ & Cohesion $(\mathrm{kPa})$ & E-modulus $(\mathrm{MPa})$ & Poisson's ratio & Unit weight $\left(\mathrm{kg} / \mathrm{m}^{3}\right)$ \\
\hline Values & 23.2 & 26.9 & 4.8 & 0.26 & 21.217 \\
\hline
\end{tabular}

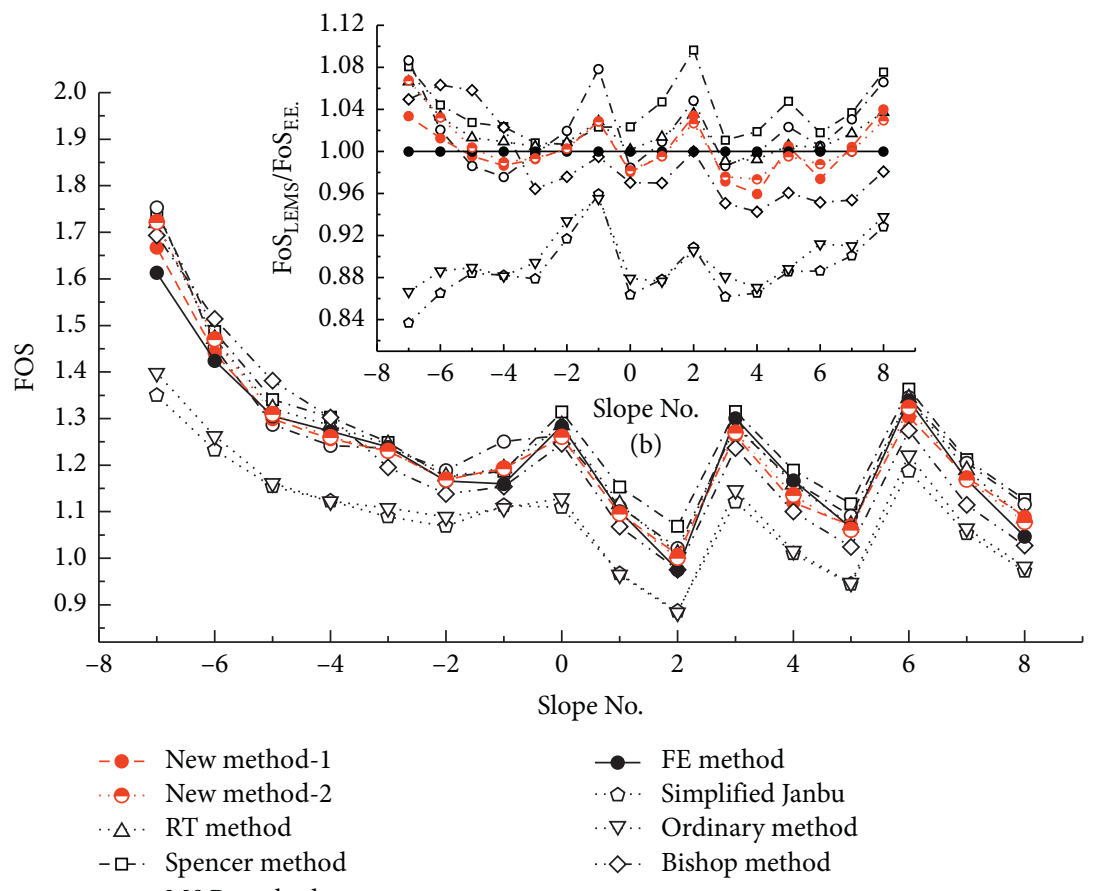

(a)

FIGURE 17: (a) FoS calculated by different methods for each slope. (b) Ratios of FoS between LEMS and the FE method for each slope.

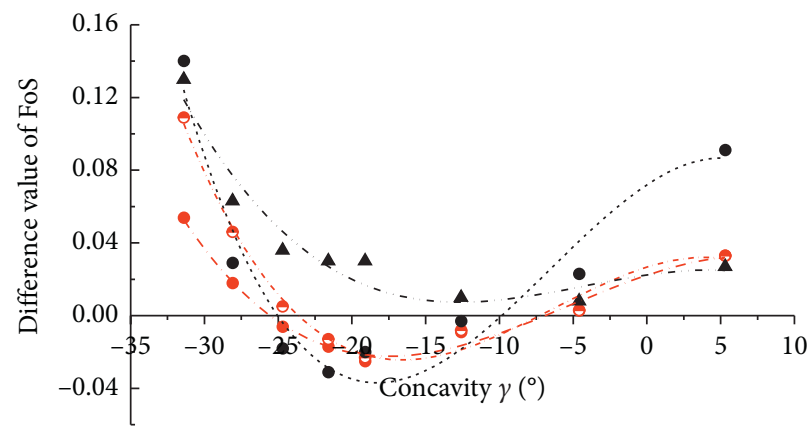

- A: Difference between new method-1 \& FE

-..-. Cubic polynomial

B: Difference between new method-2 \& FE

$\Delta$ C: Difference between Spencer method \& FE

- D: Difference between fit of A

-.-. Cubic polynomial fit of B

-.. Cubic polynomial fit of C

M\&P method \& FE

... Cubic polynomial fit of D

FIGURE 18: Variations of difference values of FoS with the concavity $\gamma$. 


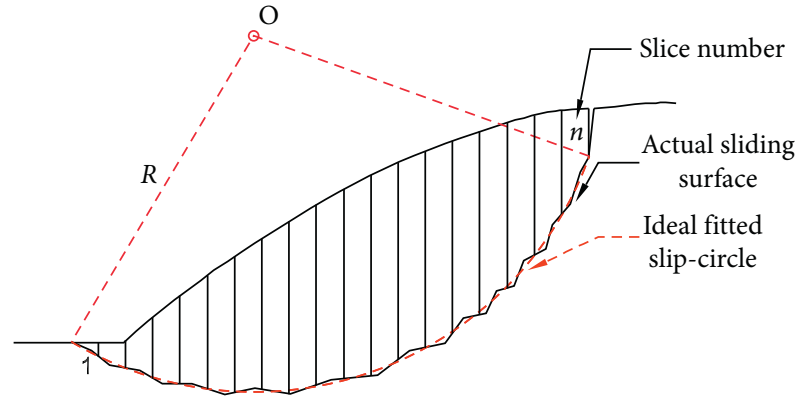

(a)

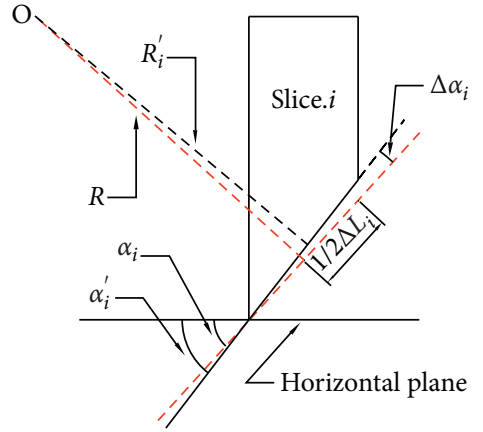

(b)

Figure 19: Schematic diagram for depicting the difference between the actual and the fitted sliding surfaces. (a) Profile of the slide. (b) Details of the slice.

the slide should be obtained as equation (14), which contains the real FoS:

$$
\sum_{i=1}^{n} Q_{i} \cdot \cos \left(\alpha_{i}^{\prime}-\theta\right) \cdot R_{i}^{\prime}=0
$$

where $\alpha_{i}^{\prime}$ is the slope of the actual base of slice. $i$ and $n$ is the number of the last slice.

In the new method, the radius of curvature for all the slice bases is united as $R$, whose relationship with $R_{i}^{\prime}$ is illustrated in Figure 19(b) and is expressed as equation (15). Thus, an approximate moment equilibrium equation for the slide is obtained as equation (16) or equation (17), where equation (16) adopts the slopes of the actual slice bases, while equation (17) adopts the fitted one. Indeed, the FoS determined by equation (16) or equation (17) (denoted as FoS $_{(16)}$ and $\mathrm{FoS}_{(17)}$, respectively) is not accurate initially. But as the fitted slip-circle approaches the actual sliding surface, equation (18) can be obtained to make $\mathrm{FoS}_{(16)}$ and $\mathrm{FoS}_{(17)}$ both close to the real value. Also the difference $\left(\Delta \mathrm{FoS}=\mathrm{FoS}_{(16)}-\mathrm{FoS}_{(17)}\right)$ between $\mathrm{FoS}_{(16)}$ and $\mathrm{FoS}_{(17)}$ will approach zero:

$$
R=\frac{R_{i}^{\prime}}{\cos \Delta \alpha_{i}}+\frac{1}{2} \cdot \Delta L_{i} \cdot \tan \Delta \alpha_{i}, \quad \Delta \alpha_{i}=\alpha_{i}^{\prime}-\alpha_{i}, \lim _{n \longrightarrow+\infty} \Delta L_{i}=0
$$

$$
\begin{aligned}
& \sum_{i=1}^{n} Q_{i} \cdot \cos \left(\alpha_{i}^{\prime}-\theta\right) \cdot R=0, \\
& \sum_{i=1}^{n} Q_{i} \cdot \cos \left(\alpha_{i}-\theta\right) \cdot R=0, \\
& \lim _{\Delta \alpha_{i} \longrightarrow 0, n \longrightarrow+\infty} \text { Eq. }(18)=\text { Eq. }(17), \\
& \lim _{\Delta \alpha_{i} \longrightarrow 0, n \longrightarrow+\infty} \text { Eq. }(19)=\text { Eq. }(17),
\end{aligned}
$$

where $\alpha_{i}$ and $\Delta L_{i}$ are the slope and the length of the fitted base of slice.i, respectively.

For example, when adopting the new method to analyse the Jinle 2\# landslide, 1 to 7 fitting arcs were tried successively to fit the actual sliding-surfaces, so as to simulate the progressive increase of the closeness degree between the actual and the fitted sliding-surfaces (see Figure 20). As expected, $\Delta$ FoS calculated shows a tendency of approaching zero as the number of fitting arcs increases (Figure 21(a)). Moreover, the decreasing mode of the absolute value of $\Delta$ FoS with the number of fitting arcs can be depicted by the power function (Figure 21(b)). This means accuracy of the new method in analysing real cases can be achieved as long as the proximity between the actual and the fitted slidingsurfaces is ensured.

4.3. Rules for the Inclinations of Interslice Forces. Figure 22 presents the coordinate points $\left(\theta_{m}, \beta_{m}\right)$ for each slip-circle within all the above calculation cases (such as $\left(\theta_{1}\right.$, $\beta_{1}$ ) for Arc.1 within slope.-7; see Figure 16), where the red points are obtained by the new method-1 and the black points are obtained by method-2. Little difference has been found for the point-locations between the new method-1 and method-2, except for some special points for the second circles of slopes Nos.1, 3, 4, and 6 (see Figures 15 and 22). Apart from the special points, the common points can be linearly fitted by a solid line, which indicates a statistical law between $\theta_{m}$ and $\beta_{m}$. Additionally, with the help of the diagonal (expressed as $\theta_{m}=\beta_{m}$ ), an abscissa of near $15^{\circ}$ is found to be the threshold value for distinguishing the relationship between $\theta_{m}$ and $\beta_{m}$ into two parts, that is, when $\beta_{m}<15^{\circ}, \theta_{m}>\beta_{m}$; or when $\beta_{m}>15^{\circ}, \theta_{m}<\beta_{m}$ (see Figure 22).

So, we surmise that $\theta_{m}$ stipulated for each slip-circle is essentially a compromise value for the real inclinations of the interslice forces. Although the appearance of some special points is frustrating, it is rare and seems to have little effect on the analysis.

4.4. Two Remaining Problems. Before discussion, we set that the resisting force that reacted between piles and sliding soils is commonly horizontal [25].

4.4.1. How to Select the Interval of Piles under the Specified Fs? In Chapter 2.2, we put forward the calculation procures for the DDF $(N)$ under the safety coefficient (Fs). Note that the unit of $N$ is $\mathrm{kN} / \mathrm{m}$, for the analysis is based on a plan strain 


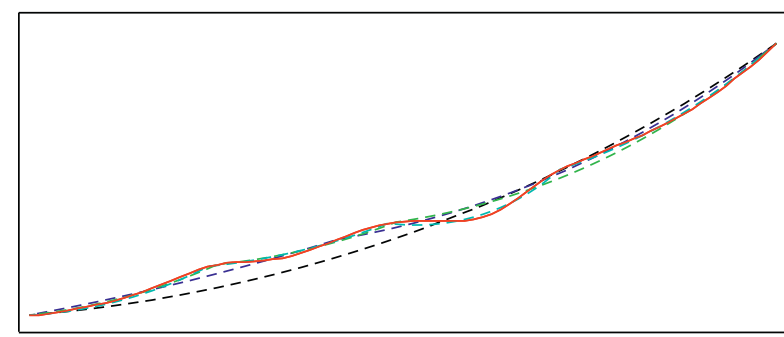

_- Actual sliding-surfaces
-- Single-arc fitting

_- Double-arc fitting

-.' Triple-arc fitting

.., Quadruple-arc fitting

(a)

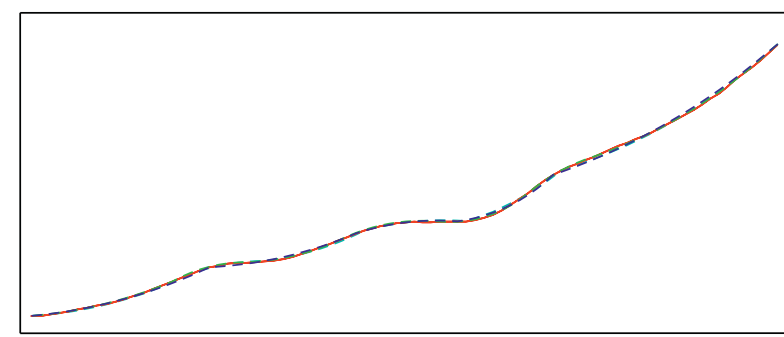

Actual sliding-surfaces _. Sextuple-arc fitting

_, Quintuple-arc fitting _.., Septuple-arc fitting

(b)

Figure 20: Fitting the actual sliding-surfaces with different number of fitting arcs. (a) 1 to 4 arcs-fitting. (b) 5 to 7 arcs-fitting.

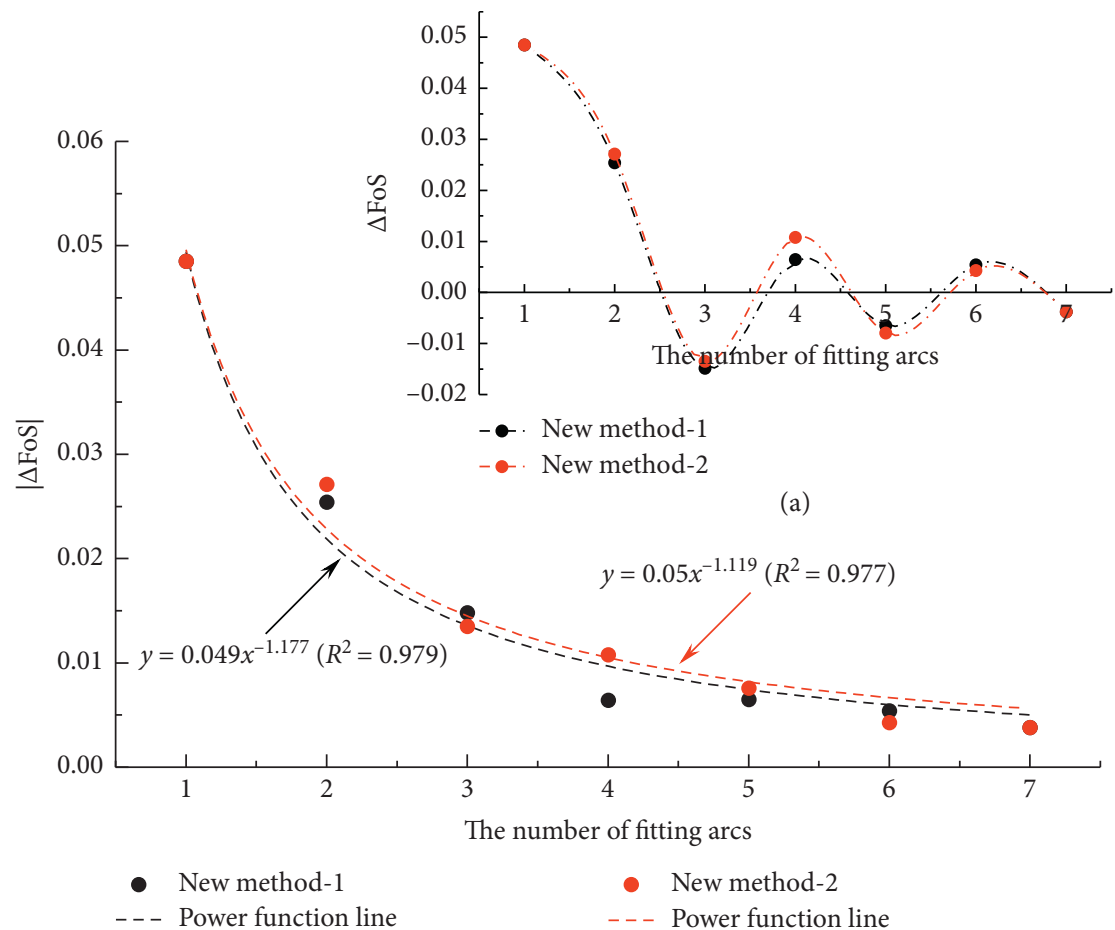

(b)

FIGURE 21: (a) $\Delta$ FoS varying with the number of fitting arcs. (b) Absolute value of $\Delta$ FoS varying with the number of fitting arcs.

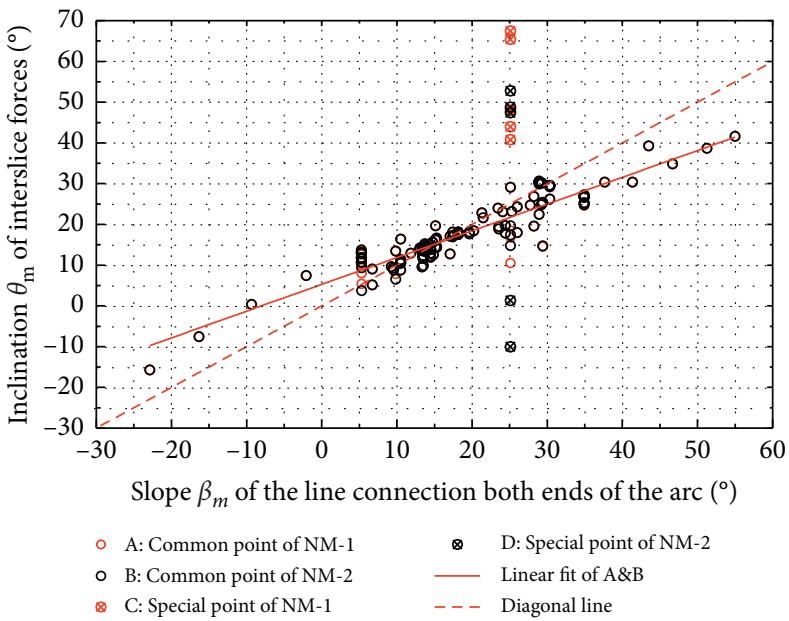

FIgURE 22: Relationship between $\theta_{m}$ and $\beta_{m}$. 
model (Figure 4). Apparently, if the piles can react that resisting force $N$ to the plan model, then the specified safety coefficient Fs could be reached. But a question of how to select a rational pile's interval on the transverse of landslide so as to mobilize that expected resisting force $\mathrm{N}$ appears. It is because the magnitude of resisting force $N(\mathrm{kN} / \mathrm{m})$ of piles is actually controlled by the soil arching that is mobilized within pile's interval.
Herein, we take the ideas from Ito et al. [25]. Figure 23(a) shows the geometric conditions of pile's interval, where $d$ is the diameter of the pile, $D_{1}$ is the centre-to-centre interval between piles, and $D_{2}$ is the clear interval between piles. Figure 23(b) shows the net resisting force $\mathrm{p}_{(\mathrm{z})}$ distributed along the pile's length, which is given by the soil arching and is acted on per unit thickness of the soil layer within pile's interval. The formula of $p_{(z)}$ is referred to the following equations:

$$
\begin{aligned}
& p(z)=f_{1}+f_{2} \cdot z, \\
& \left.f_{1}=c \prime\left(\frac{D_{1}}{D_{2}}\right)^{\left(N_{\phi^{\prime}}^{(1 / 2)} \tan \phi^{\prime}+N_{\phi^{\prime}}-1\right.}\right)\left[\frac{1}{N_{\phi^{\prime}} \tan \phi^{\prime}}\left\{\exp \left(\frac{D_{1}-D_{2}}{D_{2}} N_{\phi^{\prime}} \tan \varphi^{\prime} \tan \left(\frac{\pi}{8}+\frac{\phi^{\prime}}{4}\right)\right)-2 N_{\phi^{\prime}}^{(1 / 2)} \tan \phi^{\prime}-1\right\}\right. \\
& \left.+\frac{2 \tan \phi^{\prime}+2 N_{\phi^{\prime}}^{(1 / 2)}+N_{\phi^{\prime}}^{-(1 / 2)}}{N_{\phi^{\prime}}^{(1 / 2)} \tan \phi^{\prime}+N_{\phi^{\prime}}-1}\right] \\
& -\frac{c^{\prime}}{D_{1}}\left\{D_{1} \frac{2 \tan \phi^{\prime}+2 N_{\phi^{\prime}}^{(1 / 2)}+N_{\phi^{\prime}}^{-(1 / 2)}}{N_{\phi^{\prime}}^{(1 / 2)} \tan \phi^{\prime}+N_{\phi^{\prime}}-1}-2 D_{2} N_{\phi^{\prime}}^{-(1 / 2)}\right\} \\
& \left.f_{2}=\frac{\gamma}{N_{\phi_{1}}}\left\{\left(\frac{D_{1}}{D_{2}}\right)^{\left(N_{\phi^{\prime}}^{(1 / 2)} \tan \phi^{\prime}+N_{\phi^{\prime}}-1\right.}\right) \cdot \exp \left(\frac{D_{1}-D_{2}}{D_{2}} N_{\phi_{1}} \tan \phi^{\prime} \tan \left(\frac{\pi}{8}+\frac{\phi^{\prime}}{4}\right)\right)-\frac{D_{2}}{D_{1}}\right\}
\end{aligned}
$$

where $N_{\phi^{\prime}}=\tan ^{2}\left(\pi / 4+\phi^{\prime} / 2\right) ; \quad D_{2}=D_{1}-d$. Apparently, the force $\mathrm{p}_{(\mathrm{z})}$ along the $z$-axis is linearly distributed as shown in Figure 23(b), where $p(0)=f_{1}, p\left(z_{t}\right)=f_{1}+f_{2} \cdot z_{t}$, and $z_{t}$ is the effective length of the pile which is above the sliding surface. The resultant $P$ that the soil arching within pile's interval can give is

$$
P=\int_{0}^{z_{t}} p(z)=f_{1} \cdot z_{t}+\frac{1}{2} f_{2} z_{t}^{2} .
$$

So, the unit of $P$ is $\mathrm{kN}$. As for the resultant $P$ / acting on per unit width of pile's interval, the equation is obtained as $P \prime=P / D_{1}$.

Bringing the problem back to plane strain model, we have got the resisting force $N(\mathrm{kN} / \mathrm{m})$ in Chapter 2.2 to satisfy the expected safety Fs of landslide. Then, we make

$$
P I=N \text {. }
$$

Obviously, the pile's interval $D_{1}$ is the only unknown quantity in equation (23), so it can be solved by iterative algorithm and is noted as $D_{1 \text { (FoS) }} . D_{1 \text { (FoS) }}$ is just the answer that can make the expected resisting force $N(\mathrm{kN} / \mathrm{m})$ of piles be mobilized.

4.4.2. How to Assess the Stability of Landslide Reinforced with Piles? Another question is how to assess the stability of the landslide that is reinforced with piles with a certain value of pile's interval $D_{1}$. Herein, $D_{1}$ is a certain value specified in advance. So, according to equations (19) (23), the resisting force $N$ can be calculated as a known quantity. As shown in Figure 24, $N_{1}$ which can be regarded as the "link-force" between circles is the unknown quantity. As in Chapter 2.1, we set an initial value $\mathrm{F}_{0}$; then, according to equations (4), (7), and (8), $\left(\theta_{1}\right)_{F_{0}}$ and $\left(Z_{a}\right)_{F_{0}}$ for circle.1 can be determined. As for slice. $a+1$ in circle. 2 , the interslice resultant $Q_{a+1}$ is derived as

$$
Q_{a+1}=\frac{\left(c \cdot x_{a+1} / F\right) \cdot \sec \alpha_{a+1}+(\tan \phi / F) \cdot\left[\left(W_{a+1}+\left(Z_{a}\right)_{F_{0}}^{\prime \prime}+N \cdot \tan \theta_{2}\right) \cdot \cos \alpha_{a+1}-U_{a+1}\right]-\left(W_{a+1}+\left(Z_{a}\right)_{F_{0}}^{\prime \prime}+N \cdot \tan \theta_{2}\right) \cdot \sin \alpha_{a+1}}{\cos \left(\alpha_{a+1}-\theta_{2}\right) \cdot\left[1+(\tan \phi / F) \cdot \tan \left(\alpha_{a+1}-\theta_{2}\right)\right]} .
$$




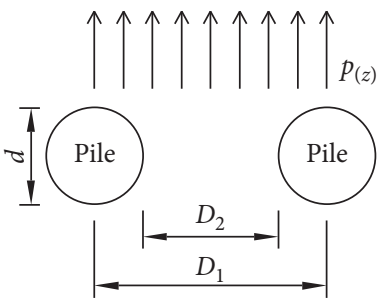

(a)

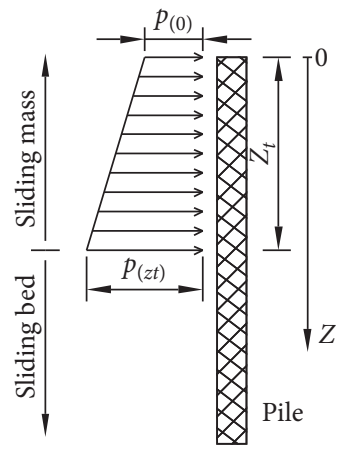

(b)

FIGURE 23: Schematic diagram of antislide piles. (a) Geometric conditions of pile's interval. (b) Distribution of the resisting force along pile's length.

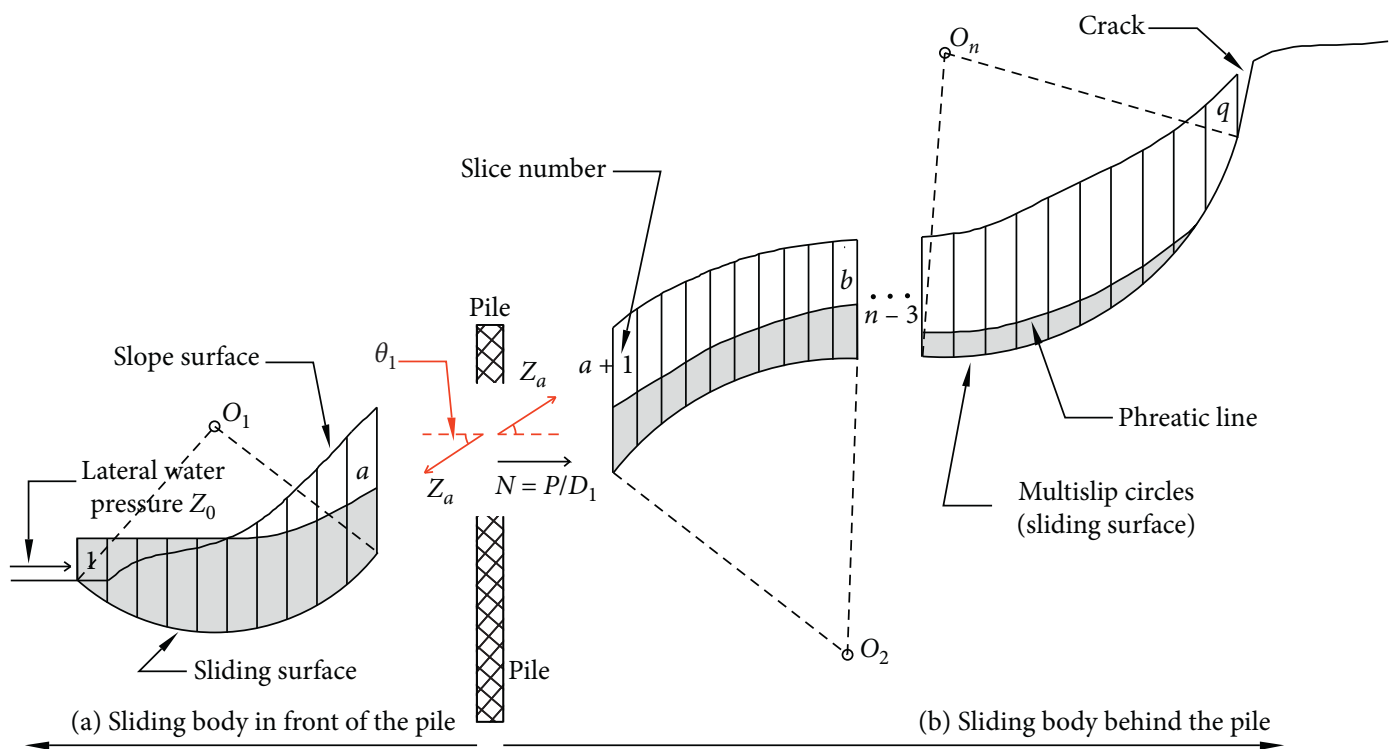

FIGURE 24: Planar model of a slope reinforced with a row of piles with a certain value of pile's interval $D_{1}$.

Similarly, the force and moment equilibrium equations for circle.2 are changed as equations (25) and (26), respectively:

$$
\begin{gathered}
Z_{b}=\sum_{i=a+1}^{b} Q_{i}+\left(Z_{a}\right)_{F_{0}}^{\prime}+N / \cos \theta_{2}, \\
\sum_{i=a+1}^{b} Q_{i} \cdot \cos \left(\alpha_{i}-\theta_{2}\right)=Z_{b} \cdot \cos \left(\alpha_{b}-\theta_{2}\right)-\left[\left(Z_{a}\right)_{F_{0}}{ }^{\prime}+N / \cos \theta_{2}\right] \cdot \cos \left(\alpha_{a+1}-\theta_{2}\right) .
\end{gathered}
$$

The comprehensive equilibrium equation for circle. 2 is

$$
\sum_{i=a+1}^{b} Q_{i} \cdot \cos \left(\alpha_{i}-\theta_{2}\right)=\left(\sum_{i=a+1}^{b} Q_{i}\right) \cdot \cos \left(\alpha_{b}-\theta_{2}\right)+\left[\left(Z_{a}\right)_{F_{0}}{ }^{\prime}+N / \cos \theta_{2}\right] \cdot\left[\cos \left(\alpha_{b}-\theta_{2}\right)-\cos \left(\alpha_{a+1}-\theta_{2}\right)\right]
$$


So, according to equations (25) (27), the two variables $\theta_{2}$ and $Z_{b}$ can be determined as $\left(\theta_{2}\right)_{F_{0}}$ and $\left(Z_{b}\right)_{F_{0}}$.

The same as Step 3 n in Chapter 2.1, the variables $\left(\theta_{m}\right.$, $\left.Z_{a / b / c . .}\right)$ relying on $\mathrm{F}_{0}$ for all the circles can be solved in turn, including $\left(Z_{q}\right)_{F_{0}}$ for the last slice.q (Figure 24). Then, by considering the boundary conditions, it should be verified whether $\left(Z_{q}\right)_{F_{0}}$ obtained equals zero. If $\left(Z_{q}\right)_{F_{0}} \neq 0$, then the value of $F_{0}$ should be adjusted repeatedly until a final $F_{0}$ is found for the FoS that makes $\left(Z_{q}\right)_{F_{0}} \approx 0$. This final $F_{0}$ can assess the stability of the landslide that is reinforced with piles with a certain pile's interval $D_{1}$.

\section{Conclusion}

Faced with the multicircular sliding-surfaces, a new method for stability analysis is proposed. In the method, the entire slip-surface is divided into several interrelated Spencer's circles, so as to ensure that each of them has a real rotation centre and an independent inclination of interslice forces. Both real cases and conceptual slopes were adopted to verify the effectiveness of the new method, from which the new method is found to be acceptable for both stability analysis and design driving forces analysis. However, the results obtained by the modified Spencer method are generally larger than those obtained by the new method (especially when the concavity $\gamma$ of the first sliding-circle is less than $-5^{\circ}$; see Figure 18), which might be ascribed to its assumption of a fictitious rotation centre and only one constant inclination for all the interslice forces [20].

Four topics discussed for the new method highlight the following: (i) the concavity $\gamma$ of the first sliding-circle plays a leading role in influencing the performance of the method, and the optimal range of it for the method is from $-25^{\circ}$ to $-5^{\circ}$; (ii) the stipulation of $\theta_{m}$ is a basis of rationality for the new method, for its value is judged as a compromise one for the real inclinations of the interslice forces within each circle; (iii) for the Jinle landslide, we find that $\Delta \mathrm{FoS}$ is decreased to 0.005 as the number of fitting arcs increases to 6 , which highlights that the proximity between the actual and the fitted sliding surfaces should be ensured when adopting the new method to real cases; and (iv) the selection of rational pile's interval is important for controlling the magnitude of resisting force $N(\mathrm{kN} / \mathrm{m})$ of piles and the assessment of stability of landslide reinforced with piles is also essential for some practical engineering problems.

Outlooks are clarified for future promotion:

(i) This paper focuses on the main sliding direction of the landslide, so a two-dimensional profile along the main sliding direction of the landslide is chosen for analysing as a plan strain problem with the new method. For real engineering problems, landslides are in three-dimensional space. Hence, the extension of the new method to its $3 \mathrm{D}$ version is essential.

(ii) Due to the rigid assumptions, the influence of deformation of sliding bodies on the accuracy of calculation cannot be considered in the slice methods. So, more targeted comparison studies made by the numerical simulations for assessing the level of that influence should be continued. Recently, the numerical manifold method is prevalent and is verified to be especially efficient in analysing the stability of slopes which are subjected to sequential excavation [33-35].

(iii) Attempts should also be made to apply the new method to capture the critical failure surfaces and to develop the stability charts. However, at present, the research in this field is generally focused on a single slip-circle.

\section{Notations}

c: Cohesion of sliding surface (with respect to effective stress)

c': Cohesion of sliding mass (with respect to effective stress)

F: $\quad$ Factor of stability (FoS)

$F_{s}$ : Specified safety coefficient of a slope reinforced with piles

$g: \quad$ Gravity coefficient $\left(\mathrm{ms}^{-2}\right)$

$h_{i-1}$ : Hydraulic height on left side of slice. $i$

$h_{i}$ : $\quad$ Hydraulic height on right side of slice. $i$

$i$ : $\quad$ Counting number of slice. The order is from toe to crest

$m$ : Counting number of circle. The order is from toe to crest

$N$ : Design driving force

$N_{1}$ : $\quad$ Resisting forces in front of pile

$N_{2}$ : $\quad$ Sliding thrusts behind pile

$P_{i}$ : $\quad$ Total reaction normal to base of slice. $i$

$P_{i}^{\prime}$ : $\quad$ Effective reaction normal to base of slice. $i$

$Q_{i}: \quad$ Generalised interslice resultant of slice. $i$

$S_{i}$ : $\quad$ Total shear force available along base of slice. $i$

$S_{i} / F: \quad$ Total shear force mobilized along base of slice. $i$

$U_{i}$ : $\quad$ Buoyant force (due to pore pressure) normal to base of slice. $i$

$W_{i}$ : Weight of slice. $i$

$x_{i}: \quad$ Width of slice. $i$

$Z_{a / b \ldots}:$ Link-force

$Z_{i-1}$ : $\quad$ Force on left side of slice. $i$

$Z_{\mathrm{i}}$ : $\quad$ Force on right side of slice. $i$

$\phi$ : $\quad$ Frictional angle of sliding surface (with respect to effective stress)

$\phi^{\prime}: \quad$ Frictional angle of sliding mass (with respect to effective stress)

$\psi: \quad$ Angle of shearing resistance between pile and soil

$\theta_{m}:$ Inclination of interslice forces of circle. $m$

$\theta: \quad$ Slope of $Z_{i-1}$

$\theta^{\prime}$ : $\quad$ Slope of $Z_{i}$

$a_{\mathrm{i}}: \quad$ Slope of base of slice. $i$

$\beta_{\mathrm{m}}$ : Slope of line connecting both ends of circle. $m$

$\gamma$ : $\quad$ Concavity of circle.1 (slope of line connecting slope toe and midpoint of circle.1).

\section{Data Availability}

All data, models, and codes generated or used during the study appear in the submitted article. 


\section{Conflicts of Interest}

The authors declare that they have no conflicts of interest.

\section{Acknowledgments}

This study was financially supported by the National Key Research and Development Program of China (Grant no. 2017YFC1501305) and the National Basic Research Program Project (973 Project) of the Ministry of Science and Technology of China (Grant no. 2011CB710600). The authors would like to thank Professor Matthew Richard Coop, CEGE Director of Research at University College London, for his helpful suggestions.

\section{References}

[1] T. Steward, N. Sivakugan, S. K. Shukla, and B. M. Das, "Taylor's slope stability charts revisited," International Journal of Geomechanics, vol. 11, no. 4, pp. 348-352, 2011.

[2] G. Sun, Y. Yang, S. Cheng, and H. Zheng, "Phreatic line calculation and stability analysis of slopes under the combined effect of reservoir water level fluctuations and rainfall," $\mathrm{Ca}$ nadian Geotechnical Journal, vol. 54, no. 5, pp. 631-645, 2017.

[3] W. Fellenius, Statistical Analysis of Earth Slopes and Retaining Walls Considering Both Friction and Cohesion and Assuming Cylindrical Sliding Surfaces, W. Ernst und Sohn, Berlin, Germany, 1927.

[4] W. Fellenius, "Calculation of the stability of earth dams," Proceedings of the Second Congress on Large Dams, vol. 4, pp. 445-463, 1936.

[5] K. E. Petterson, "The early history of circular sliding surfaces," Géotechnique, vol. 5, no. 4, pp. 275-296, 1955.

[6] D. W. Taylor, "Stability of earth slopes," Journal of the Boston Society of Civil Engineers, vol. 24, pp. 197-246, 1937.

[7] A. W. Bishop and N. Morgenstern, "Stability coefficients for earth slopes," Géotechnique, vol. 10, no. 4, pp. 129-153, 1960.

[8] E. Spencer, "A method of analysis of the stability of embankments assuming parallel inter-slice forces," Géotechnique, vol. 17, no. 1, pp. 11-26, 1967.

[9] K. Fan, D. G. Fredlund, and G. W. Wilson, "An interslice force function for limit equilibrium slope stability analysis," Canadian Geotechnical Journal, vol. 23, no. 3, pp. 287-296, 1986.

[10] J. Krahn, “The 2001 R.M. Hardy Lecture: the limits of limit equilibrium analyses," Canadian Geotechnical Journal, vol. 40, no. 3, pp. 643-660, 2003.

[11] N. R. Morgenstern and V. E. Price, "The analysis of the stability of general slip surfaces," Géotechnique, vol. 15, no. 1, pp. 79-93, 1965.

[12] Z.-Y. Chen and N. R. Morgenstern, "Extensions to the generalized method of slices for stability analysis," Canadian Geotechnical Journal, vol. 20, no. 1, pp. 104-119, 1983.

[13] J. M. Duncan, "State of the art: limit equilibrium and finiteelement analysis of slopes," Journal of Geotechnical Engineering, vol. 122, no. 7, pp. 577-596, 1996.

[14] D. Y. Zhu, C. F. Lee, Q. H. Qian, and G. R. Chen, “A concise algorithm for computing the factor of safety using the Morgenstern-Price method," Canadian Geotechnical Journal, vol. 42, no. 1, pp. 272-278, 2005.

[15] E. Spencer, "Thrust line criterion in embankment stability analysis," Géotechnique, vol. 23, no. 1, pp. 85-100, 1973.
[16] N. Janbu, "Slope Stability computations," in EmbankmentDam Engineering, R. C. Hirschfield and S. J. Poulos, Eds., pp. 47-86, John Wiley, New York, NY, USA, 1973.

[17] D. Y. Zhu, C. F. Lee, and H. D. Jiang, "Generalised framework of limit equilibrium methods for slope stability analysis," Géotechnique, vol. 53, no. 4, pp. 377-395, 2003.

[18] Y. M. Cheng, D. Z. Li, L. Li, Y. J. Sun, R. Baker, and Y. Yang, "Limit equilibrium method based on an approximate lower bound method with a variable factor of safety that can consider residual strength," Computers and Geotechnics, vol. 38, no. 5, pp. 623-637, 2011.

[19] D. G. Fredlund and J. Krahn, "Comparison of slope stability methods of analysis," Canadian Geotechnical Journal, vol. 14, no. 3, pp. 429-439, 1977.

[20] D. G. Fredlund, Z. M. Zhang, and L. Lam, "Effect of the axis of moment equilibrium in slope stability analysis," Canadian Geotechnical Journal, vol. 29, no. 3, pp. 456-465, 1992.

[21] L. Peng, R. Niu, B. Huang, X. Wu, Y. Zhao, and R. Ye, "Landslide susceptibility mapping based on rough set theory and support vector machines: a case of the Three Gorges area, China," Geomorphology, vol. 204, no. 1, pp. 287-301, 2014.

[22] C. Li, X. Wang, H. Tang, G. Lei, J. Yan, and Y. Zhang, "A preliminary study on the location of the stabilizing piles for colluvial landslides with interbedding hard and soft bedrocks," Engineering Geology, vol. 224, pp. 15-28, 2017.

[23] Q. Tan, H. Tang, L. Huang, C. Li, and T. Kou, "LSP methodology for determining the optimal stabilizing pile location for step-shaped soil sliding," Engineering Geology, vol. 232, pp. 56-67, 2018.

[24] Y.-Y. Jiao, H.-Q. Zhang, H.-M. Tang, X.-L. Zhang, A. C. Adoko, and H.-N. Tian, "Simulating the process of reservoir-impoundment-induced landslide using the extended DDA method," Engineering Geology, vol. 182, pp. 37-48, 2014.

[25] T. Ito, T. Matsui, and W. P. Hong, "Design method for stabilizing piles against landslide-one row of piles," Soils and Foundations, vol. 21, no. 1, pp. 21-37, 1981.

[26] Y. Takuo, J. C. Jiang, and U. Katsutoshi, "A limit equilibrium stability analysis of slopes with stabilizing piles," in Proceedings of the Sessions of Geo-Denver 2000, ASCE, Denver, CO, USA, pp. 343-354, August 2000.

[27] Z. Q. Fan, H. M. Tang, D. J. Wang, K. Liu, and T. Wen, “A method for designed thrust of anti-slide pile considering strain softening properties of soil," Rock and Soil Mechanics, vol. 37, no. s2, pp. 665-672, 2016, in Chinese.

[28] X. L. Hu, M. P. David, Z. Lidija, and L. Q. Wang, "Jinle landslide stability under water level fluctuation of three Gorges reservoir," Earth Science: Journal of China University of Geosciences, vol. 32, no. 3, pp. 403-408, 2007.

[29] H. Tang, C. Li, X. Hu et al., "Evolution characteristics of the Huangtupo landslide based on in situ tunneling and monitoring," Landslides, vol. 12, no. 3, pp. 511-521, 2015.

[30] Z. Q. Fan, H. M. Tang, Q. W. Tan, Y. M. Yang, and T. Wen, "Ring shear tests on slip soils and their enlightenment to critical strength of reservoir landslides," Chinese Journal of Geotechnical Engineering, vol. 41, no. 9, pp. 1698-1706, 2019.

[31] W. D. Ni, H. M. Tang, X. L. Hu, Y. P. Wu, and A. J. Su, "Research on deformation and stability evolution law of Huangtupo riverside slump-mass No. I," Rock and Soil Mechanics, vol. 34, no. 10, pp. 2961-2970, 2014, in Chinese.

[32] C. Y. Lee, T. S. Hull, and H. G. Poulos, "Simplified pile-slope stability analysis," Computers and Geotechnics, vol. 17, no. 1, pp. 1-16, 1995. 
[33] Y. Yang, G. Sun, H. Zheng, and Y. Qi, "Investigation of the sequential excavation of a soil-rock-mixture slope using the numerical manifold method," Engineering Geology, vol. 256, pp. 93-109, 2019.

[34] Y. Yang, Y. Sun, G. Sun, and H. Zheng, "Sequential excavation analysis of soil-rock-mixture slopes using an improved numerical manifold method with multiple layers of mathematical cover systems," Engineering Geology, vol. 261, Article ID 105278, 2019.

[35] Y. Yang, G. Sun, H. Zheng, and C. Yan, “An improved numerical manifold method with multiple layers of mathematical cover systems for the stability analysis of soil-rockmixture slopes," Engineering Geology, vol. 264, Article ID 105373, 2020. 